\title{
WestVirginiaUniversity
}

THE RESEARCH REPOSITORY @ WVU

Graduate Theses, Dissertations, and Problem Reports

2012

\section{Examination of Mediational Models of the Hostility-Health Link}

\author{
Carol Goulet \\ West Virginia University
}

Follow this and additional works at: https://researchrepository.wvu.edu/etd

\section{Recommended Citation}

Goulet, Carol, "Examination of Mediational Models of the Hostility-Health Link" (2012). Graduate Theses, Dissertations, and Problem Reports. 4860.

https://researchrepository.wvu.edu/etd/4860

This Thesis is protected by copyright and/or related rights. It has been brought to you by the The Research Repository @ WVU with permission from the rights-holder(s). You are free to use this Thesis in any way that is permitted by the copyright and related rights legislation that applies to your use. For other uses you must obtain permission from the rights-holder(s) directly, unless additional rights are indicated by a Creative Commons license in the record and/ or on the work itself. This Thesis has been accepted for inclusion in WVU Graduate Theses, Dissertations, and Problem Reports collection by an authorized administrator of The Research Repository @ WVU. For more information, please contact researchrepository@mail.wvu.edu. 
Examination of Mediational Models of the Hostility-Health Link

\title{
Carol Goulet
}

\author{
Thesis submitted to the \\ Eberly College of Arts \& Sciences \\ at West Virginia University \\ in partial fulfillment of the requirements \\ for the degree of
}

\author{
Master of Science \\ in \\ Psychology
}

\author{
Kevin Larkin, Ph.D., Chair \\ Amy Fiske, Ph.D. \\ Aaron Metzger, Ph.D. \\ Department of Psychology \\ Morgantown, West Virginia \\ 2012
}

Keywords: Hostility, Health Behavior, Virtuous Behavior, Health Copyright 2012 Carol Goulet 


\title{
ABSTRACT \\ Examination of Mediational Models of the Hostility-Health Link
}

\author{
Carol Goulet
}

This study investigated health behavior as a possible mediator of the link between hostility and poor physical and psychological health. The relations of health behavior, character strength, and virtuous behavior to hostility and health were also examined. A sample of 689 undergraduate participants (69.4\% female) completed a series of on-line assessments that measured hostility, physical health, psychological health, health behavior, social support, character strength, and virtuous behavior. Health behavior was examined and found to be a significant partial mediator of the relations between hostility and physical and psychological health. Furthermore, the results of multiple regressions revealed that gender, hostility, and health behavior were meaningfully related to physical health, and gender, hostility, and virtuous behavior significantly predicted psychological health. Together these findings indicated that interventions designed to improve health outcomes for hostile individuals with an emphasis on engagement in health behaviors and virtuous behaviors should be devised and tested. 


\section{Acknowledgements}

First, I would like to express appreciation for Dr. Kevin Larkin, my advisor and committee chair, for his patience, guidance, and willingness to share his expertise throughout the project.

I would also like to thank my committee members, Dr. Amy Fiske and Dr. Aaron Metzger, for their efforts and advice throughout.

Finally, I would like to thank Dr. Lynda Szymanski, my undergraduate mentor, and Dr. Stacy Symons, another very influential undergraduate professor, for sparking my interest in psychology. 


\section{Table of Contents}

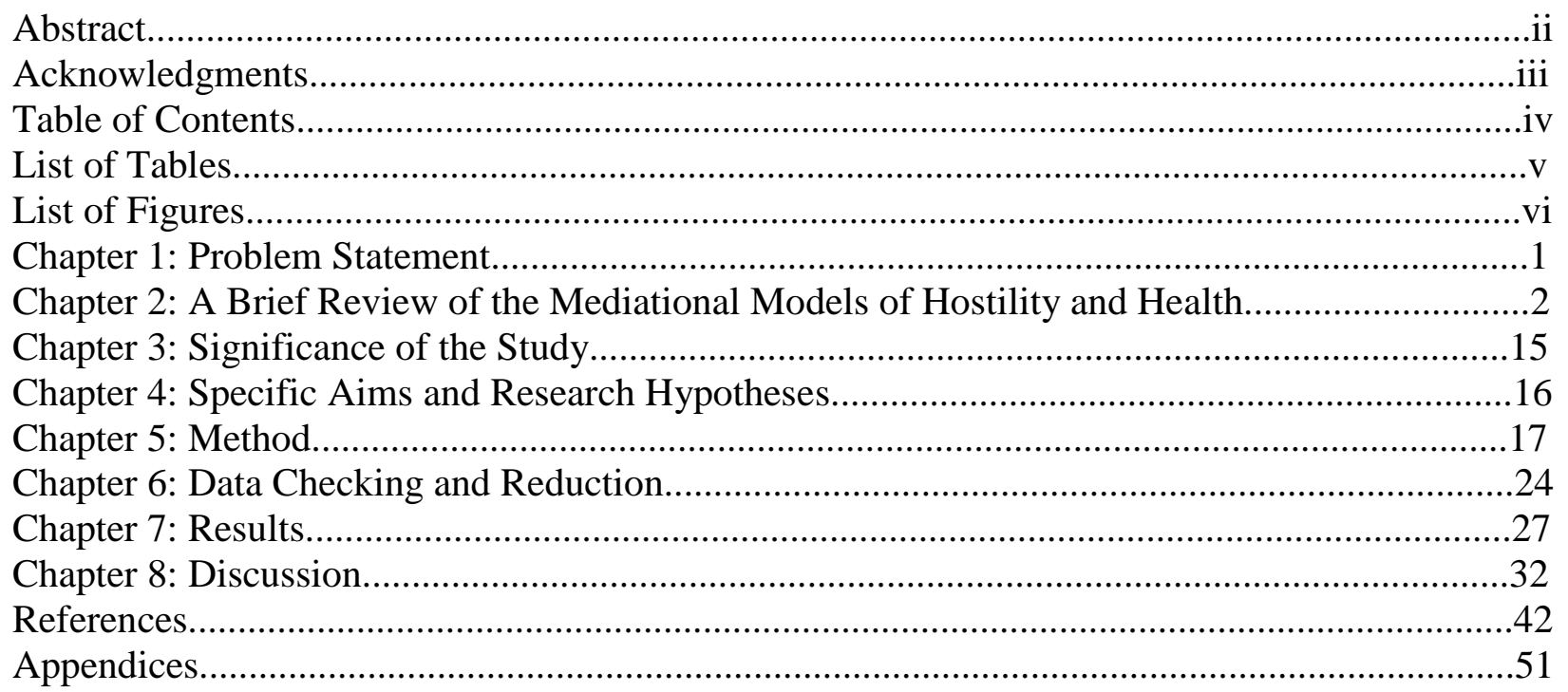




\section{List of Tables}

Table 1: Character Strengths and Virtues Terms and Definitions...........................................51

Table 2: T-tests Comparing Study Variables by Participant Sex................................................53

Table 3: Descriptive and Normality Distribution Information for Study Variables.....................54

Table 4: T-tests Comparing Study Variables by VIA Completion Status.......................................55

Table 5: Correlations among Measures of Hostility, Physical Health, Psychological Health,

Health Behavior, Character Strength, and Virtuous Behavior........................................56

Table 6: Mediation of the Hostility-Physical Health Relation.....................................................57

Table 7: Mediation of the Hostility-Psychological Health Relation.............................................58

Table 8: Hierarchical Regression Predicting Physical Health.................................................59

Table 9: Hierarchical Regression Predicting Psychological Health........................................61

Table 10: Hierarchical Regression Predicting Physical Health, Excluding the VIA...................63

Table 11: Hierarchical Regression Predicting Psychological Health, Excluding the VIA...........65

Table 12: Factor Structure of the VIA Proposed by Peterson and Seligman (2004)....................70

Table 13: Factor Structure of VIA Derived from EFA of Participants with Even-numbered

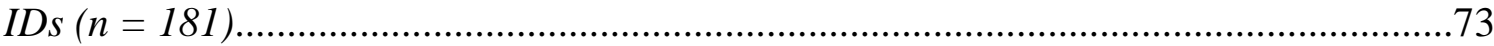

Table 14: Factor Structure of VIA Derived from EFA of Participants of Odd-numbered IDs

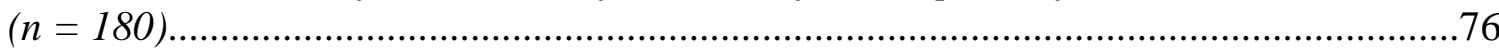

Table 15: Factor Structure of VIA Derived from EFA of All Participants $(n=361) \ldots . . . . . . . . . . . . . .79$

Table 16: Factor Structure of VIA Proposed by MacDonald, Bore, and Munro (2008)...............82

Table 17: Factor Structure of VIA Proposed by Ruch et al. (2010).............................................85

Table 18: Factor Structure of VIA Proposed by Singh and Choubisa (2010).............................88

Table 19: Model Fit of CFAs for Proposed VIA Factor Structure ...............................................91

Table 20: Forced One-factor Factor Structure of VIA Derived from EFA of All Participants $(n=361)$ 


\section{List of Figures}

Figure 1: Participant Exclusion Flowchart.............................................................................67

Figure 2: Confirmatory Factor Analysis of VIA Factor Structure Proposed by Peterson and Seligman (2004)...........................................................................................................

Figure 3: CFA on Data from Even-numbered Participants Derived from EFA of Participants with Even-numbered IDs.

Figure 4: CFA on Data from Odd-numbered Participants Derived from EFA of Participants with Odd-numbered IDs.

Figure 5: CFA Derived from EFA of All Participants...................................................................

Figure 6: CFA of VIA Factor Structure Proposed by MacDonald, Bore, and Munro (2008).......84

Figure 7: CFA of VIA Factor Structure Proposed by Ruch et al. (2010).....................................87

Figure 8: CFA of VIA Factor Structure Proposed by Singh and Choubisa (2010).......................90 


\section{Examination of Mediational Models of the Hostility-Health Link \\ Chapter 1: Problem Statement}

Empirical research has consistently supported a link between hostility and poor physical and psychological health (Hecker, Chesney, Black, \& Frautschi, 1988; Miller, Smith, Turner, Guijarro, \& Hallet, 1996). It is generally accepted that hostility refers to a set of negative beliefs about the untrustworthy nature of others (Smith, 1992). However, it is unclear how hostile beliefs, mere cognitions, are linked to negative health outcomes. Multiple mediational models have been proposed in an attempt to explain the link between hostility and health, including increased physiological reactivity, deficits in psychosocial factors, and engagement in poor health behaviors. Despite extensive research on this phenomenon over the past few decades, it remains unclear which of these models best explain the hostility-health link. Therefore, the purpose the study presented is twofold: (a) to examine evidence for a few of these proposed mediational models to explain the relation between hostility and poor physical and psychological health, and (b) to explore the relations between character strength, virtuous behavior, and the hostility-health link.

\section{Hostility and Health}

For multiple decades, the medical community has recognized a link between hostility and coronary heart disease. For example, Williams et al. (1980) investigated Type A behavior and hostility as potential predictors of coronary artery disease (CAD) in 424 patients undergoing coronary angiography. After conducting multivariate analyses, the researchers found that both variables were associated with CAD, but hostility was a stronger predictor of CAD than Type A behavior. Furthermore, hostility has been linked to increased platelet aggregation (Shimbo et al., 2009), high blood pressure (Brondolo et al., 2009, Lazaro, Valdes, Marcos, \& Guarch, 1993), 
Mediating the Hostility-Health Link 2

and elevated total serum cholesterol (Hillbrand et al., 2005)—all factors believed to be related to poor cardiovascular health.

More recently, this link has been extensively examined and expanded, broadening the link between hostility and other adverse health conditions. Notably, hostility has been linked to greater frequencies of sleep disturbances (Dahl, 2006; Grano, Vahtera, Keltikangas-Jarvinen, \& Kivimaki, 2008), development of flu-like symptoms in older adults (Gidron, Hassid, Yisrael, \& Biderman, 2005), migraines and neck pain (Johnson, 2003), susceptibility to colds (Evans \& Edgerton, 1992), and an increased vulnerability to illness when stressed (Lee et al., 1995). Hostility has also been linked to poor psychological health. High rates of hostility has been associated with depressive symptoms (Kopp, Stauder, Purebl, Janszky, \& Skrabski, 2008; Siegel, Yancey, \& McCarthy, 2000), increased rates of suicidal thoughts (Engin, Gurkan, Dulgerler, \& Arabaci, 2009) as well as muscle dysmorphia in men (Maida \& Armstrong, 2005). Perhaps the most disturbing health-related finding was reported by Miller et al. (1996), whose meta-analysis linked high levels of hostility to higher overall mortality rates. Although research largely supports a link between hostility and poor health, it is unknown how hostile cognitions promote poor physical and psychological health. However, multiple theoretical models have been developed to help advance our understanding of the hostility-health link.

\section{Chapter 2: A Brief Review of the Mediational Models of Hostility and Health}

In 1992, after reviewing the hostility and health literature, Smith proposed five models that explain how hostility may impact health outcomes. These models, which will be briefly introduced below, include the psychophysiological reactivity model, psychosocial vulnerability model, transactional model, health behavior model, and constitutional vulnerability model. 
Mediating the Hostility-Health Link 3

\section{Psychophysiological Reactivity Model}

The psychophysiological reactivity model was developed by Williams, Barefoot, and Shekelle (1985). According to this model, enhanced cardiovascular and neuroendocrine reactivity mediates the relation between hostility and poor health. Essentially, high hostile individuals were hypothesized to experience heightened levels of stress hormones, blood pressure, and heart rate when exposed to stressors, in contrast to low hostile counterparts. Greater psychophysiological reactivity experienced by high hostile individuals may also result from more frequent or more intense bouts of anger or from periods of hypervigilence for signs of threat from the environment. Williams et al. suggested that this chronic heightened reactivity to stress may actually increase risk for developing cardiovascular diseases, while excessive release of stress hormones may weaken the immune system, making hostile individuals more susceptible to develop other diseases.

The first to test this model, Christensen and Smith (1993) recruited 60 men, who were categorized as being either high or low hostile after completing the Cook-Medley Hostility Scale (Cook \& Medley, 1954), the most commonly cited measure of hostility that has been reliably associated with negative health outcomes. The men’s blood pressure reactivity was measured after they were exposed to a lab stressor. Christensen and Smith reported that the high hostile men exhibited greater blood pressure reactivity in response to the lab stressor than did the low hostile men. The authors concluded that their findings supported the psychophysiological reactivity model of hostility and health because a lifetime of excessive reactivity may lead to poorer health outcomes among high hostile men. In contrast, Brondolo et al. (2003) also examined the psychophysiological reactivity model, but they found that hostile individuals did not have elevated blood pressure or even elevated heart rate reactivity to similar stressors. To 
complicate our understanding on this model further, Hernandez, Larkin, and Whited (2009) found that high hostile men were less reactive to interpersonal stress than low-hostile men. Representing the dozens of studies examining the psychophysiological reactivity model over the past two decades, inconsistent findings have shed very little understanding regarding the role of psychophysiological reactivity to stress in mediating the hostility-health link.

\section{Psychosocial Vulnerability Model}

The psychosocial vulnerability model suggests that hostile individuals experience greater interpersonal conflict and less social support than non-hostile individuals (Smith, 1992). Because they experience more conflict but lack social support to help manage their added stress, high hostile persons are more susceptible to experiencing the negative repercussions of stress, and are thus more likely to develop disease than low hostile persons. Smith proposed that this deficit in psychosocial functioning, in particular lacking a social support network, may mediate the link between hostility and health.

Grothe, Bodenlos, Whitehead, Olivier, and Brantley (2008) investigated the psychosocial vulnerability model among 95 African American patients with CHD and 30 healthy control participants. The CHD patients reported significantly higher levels of hostility than did the controls, and the researchers found that hostility was negatively correlated with social support. When social support was added to a hostility-health regression model, the correlation between hostility and health decreased, suggesting that social support partially mediated the relation between hostility and health. Additionally, Heponiemi et al. (2006) found that hostility and perceived social support were significantly related $(r=.08, p<.01)$. Similarly, Hart and Hope (2004) found a significant relation between hostility and perceived social support after 
controlling for trait neuroticism $(r=.13, p<.05)$; however, despite these significant findings, the correlations in these studies are small. In contrast, Hamden-Mansour (2010) investigated the relation between hostility and social support in 428 Jordanian university students, and found that neither family nor friend social support was a significant predictor of hostility. Although the magnitude of these effects are small and they are not reliably observed across studies, these findings suggest that social support may be at least a partial mediator of this relation.

\section{Transactional Model}

Smith (1992) also proposed the transactional model of hostility and health. This model suggested that hostile individuals actually create and prolong interpersonal stressors by mistrusting others, by wrongfully perceiving others as being hostile, by expecting others to mistreat or provoke them, and by exhibiting overt aggressive behaviors toward others. The transactional model combined the heightened reactivity of the psychophysiological model and the enhanced interpersonal conflict of the psychosocial vulnerability model to explain how these self-maintained stressors ultimately promoted negative health. According to this model, hostility was linked to adverse health conditions due to the interaction between elevated psychophysiological reactivity and frequent interpersonal conflict that occurred as a result of their characteristic mistrust of others.

Benotsch, Christensen, and McKelvey (1997) investigated the transactional model of hostility and health in 48 college students. They examined ambulatory blood pressure and daily interpersonal conflict. Benotsch et al. found that high hostile individuals experienced more interpersonal conflict, less social support, and greater ambulatory blood pressure than low hostile individuals. Similar results supporting the transactional model were found by Hardy and Smith 
(1988). Furthermore, Brondolo et al. (2003) examined the link between hostility, interpersonal conflict, and blood pressure and heart rate reactivity. Hostility was positively correlated with frequency of negative interactions but negatively correlated with frequency of positive interactions. However, hostility was not linked to either elevated blood pressure or heart rate reactivity in this study. These findings do not fully support the transactional model because hostile individuals experienced more frequent interpersonal conflict than non-hostile individuals, but not greater psychophysiological reactivity. Similar to the psychophysiological reactivity model, inconsistent findings from studies examining the transactional model raise questions about this model fully explaining the link between hostility and health outcomes.

\section{Health Behavior Model}

Smith's (1992) fourth model of hostility and health was the health behavior model. According to this model, hostile individuals were hypothesized to be vulnerable to poor health because they were less likely to engage in health promoting behaviors such as exercising and limiting alcohol consumption. Empirical research has linked hostility to engagement in a number of poor health behaviors including aggressive driving (Harris \& Houston, 2010), alcohol consumption, tobacco use, and drug use (Schwinn, Schinke $\&$ Trent, 2010), and poor physical fitness and poor self-care (Leiker \& Hailey, 1988). Smith suggested that hostile individuals experienced higher rates of physical and psychological health problems because they simply did not engage in preventative health behaviors as frequently as low hostile individuals.

To test the health behavior model, Christensen et al. (2004) investigated the health behaviors of 3,426 Danish men and 3,699 Danish women aged 40-50 years old. The participants completed questionnaires assessing physical and mental health symptoms, hostility, and health 
behaviors including: alcohol consumption, smoking, physical activity, and body mass index. Although hostility was positively correlated with number of reported health symptoms, the hostility-health link was not mediated by the health behaviors. Additionally, Miller, Markides, Chiriboga, and Ray (1995) reported a link between hostility and health behaviors; in particular, excessive alcohol consumption was predicted by hostility. Therefore, it is apparent that findings supporting the health behavior model, like the research on the other models, are inconsistent and do not consistently explain the relation between hostility and health.

\section{Constitutional Vulnerability Model}

The final mediational model of the hostility-health link is the constitutional vulnerability model. This model suggested that there was a biological explanation for hostile individuals' vulnerability to poor health. Essentially, hostile personality traits may be linked to a genetic susceptibility to develop disease. This genetic susceptibility may be related to experiencing heightened physiological reactivity or possessing some other neuroendocrine vulnerability. Therefore, this model suggests that hostile individuals may be biologically vulnerable to creating an environment that is harmful to their physical and psychological health through elevated physiological reactivity and exposure to psychosocial stress.

There has been increasing interest in the role that genetics plays in trait development and behavior. While finding a single genetic component to hostility is unlikely, multiple genes have been linked to hostility and even stress vulnerability (Wasserman, Geijer, Sokolowski, Rozanov, \& Wasserman, 2008). In particular, Wasserman et al. reported that hostility was linked to variation in a gene involved in regulating the hypothalamic-pituitary-adrenocortical axis (HPA). This finding suggested that there was a genetic component to both hostility and physiological 
reactivity to stress. However, Iwata et al. (2004) conducted a genomic scan for candidate genes and found no significant linkages with hostility. Once again, the findings are inconsistent regarding the genetic nature of hostility and its linkage with health consequences.

\section{Examining the Psychosocial Vulnerability and Health Behavior Models}

We conducted a secondary data analysis to test the Health Behavior and Psychosocial Vulnerability Models in 253 undergraduate students (Goulet \& Larkin, 2011). Congruent with previous research, hostility and physical health symptoms were positively correlated, $r=.44, p<$ .001 , as were hostility and psychological health symptoms, $r=.42, p<.001$. Social support was a significant partial mediator for relations between hostility and both physical and psychological health outcomes, which is consistent with past research (e.g., Grothe et al., 2008). Health behavior was not a significant mediator of either hostility-health relation. Although this finding provides some support for the Psychosocial Vulnerability Model, hostility remained a significant predictor of health, suggesting that limited social support by no means fully explains the hostility-health relation.

Although the link between hostility and health has been widely supported, two decades of research investigating Smith’s proposed mediational models have yet to conclusively identify how hostile cognitions are linked to poor health outcomes. No known model has consistently or thoroughly explained this link, and our data analysis confirms this general state in the literature. Therefore, the purpose of this study was to investigate other variables that may be linked to hostility and health to broaden our understanding of this relation.

\section{Conceptualization of Character Strengths}


In the past decade, character strength and other positive psychology variables have been increasingly studied as researchers attempt to identify variables that promote positive health and happiness rather than negative outcomes (Linley et al., 2007; Peterson \& Seligman, 2004). In 2004, Christopher Peterson and Martin Seligman published a list of 24 character strengths, which they divided into six theoretical factors (see Table 1). Character strengths are relatively stable and are culturally valued and refined through experience (Linley et al. 2007). Because character strengths can be modified, there are significant individual differences in possession of these strengths. Peterson and Seligman (2004) hypothesized a positive relation between use of one’s strengths and well-being. They also noted that many positive psychology concepts, such as hope and optimism, have been extensively examined, but are often done so in isolation from other relevant concepts. They proposed that these strengths share characteristics; therefore, they should be conceptualized as parts of a collective framework, which should be the focus of examination. This thinking is the origin of the development of their character strengths. However, research on these traits in their totality has been limited, primarily examining the relations between character strengths and positive affect, life satisfaction, and self-esteem (Peterson \& Seligman, 2004).

Character strengths are measured using a questionnaire titled the Values in Action Inventory of Strengths Scale (VIA; Seligman \& Park, 2004). The VIA is designed to identify an individuals' profile of character strengths, recognizing that while people have many strengths, some are stronger than others. Because Peterson and Seligman conceptualized character strengths as being multifaceted, items on the VIA pertain to emotions, cognitions, and behaviors associated with each character strength. The VIA is the only known measure that assesses character strengths as enumerated by Peterson and Seligman, and it has been completed online by over 400,000 people (Linley et al., 2007). 


\section{Cross-culture Examination of Character Strengths}

Peterson, Park, and Seligman (2006a) investigated the universal nature of these traits using a web-based survey study of 117,676 adult participants from all 50 U.S. states and 54 countries. Each character strength, except Religion, was endorsed by participants from all states and countries, suggesting that there were very few cultural differences in the presentation of the range of character strengths identified using the VIA. Peterson et al. (2006a) concluded that these strengths may be universal to human nature and fundamental to social functioning. Similarly, Biswas-Diener (2006) found that all 24 character strengths were endorsed and perceived as being socially important by citizens of Kenya, Northern Greenland, and the United States.

Cultural comparisons examining value rankings of character strengths have also been conducted. Shimai, Otake, Park, Peterson, and Seligman (2004) compared rankings of character strengths by Japanese and American participants. The Japanese participants gave lower ratings for strengths such as Humor, Perspective, and Honesty and higher ratings for Hope, Gratitude, and Fairness than the American participants. However, sex differences in rankings were similar across cultures. Japanese and American females gave higher value ratings for strengths such as Kindness and Teamwork than their male counterparts, who gave higher value ratings for strengths such as Creativity and Judgment. Additionally, Linley et al. (2007) investigated sex differences in a sample from the United Kingdom. They found that women endorsed greater levels of character strengths than men, but four of the top five endorsed traits were the same for men and women (Open-mindedness, Fairness, Curiosity, and Love of Learning). Furthermore, character strengths tended to increase across the lifespan; however, the magnitude of these sex and age effects was quite small. 


\section{Development of Character Strengths}

It is colloquially believed that experiencing hardship builds character. Peterson, Park, Pole, D’Andrea, and Seligman (2008) examined this belief by investigating the influence of traumatic life experiences on development of character strengths in a web-based survey completed by 1,739 adults. The researchers reported small but positive correlations between the frequency of experiencing traumatic events and character strengths, suggesting that character development may be stimulated when one experiences traumatic events during their lifetime. Peterson, Park, and Seligman (2006b) reported similar findings for individuals who experienced physical illnesses. Additionally, Peterson and Seligman (2003) reported that ratings of character strengths increased in U.S. citizens two months after the September $11^{\text {th }}$ terrorist attacks, and remained elevated, albeit somewhat diminished, ten months later. These studies suggest that character strengths may be influenced by both personal and global experiences; however, the sustainability of these effects is unclear.

Although research examining Peterson and Seligman's character strengths is expanding, there have been no known studies comparing character strengths to hostility, and few studies comparing it to health outcomes in general. In two such studies, Huta and Hawley (2008) examined the relation between depression and the Transcendence subscale of the VIA. Participants in Study 1 were 241 undergraduate students (66\% female) with sub-clinical levels of depression. Participants in Study 2 were 54 adults (66\% female) participating in out-patient cognitive-behavior therapy for depression. The Transcendence subscale was negatively linked to depression in Study 1 but not in Study 2. It is unclear why the relation between character strengths and depression was absent in the clinical population; however, these results suggest 
that Peterson and Seligman's character strengths may, at the very least, be negatively related to psychological health in the general population.

Additionally, Ma et al. (2008) investigated the link between character strengths and attitudes and behaviors related to drug use and sexual intercourse in 383 African American adolescents (50.1\% female) using a measure of 9 of the 24 VIA subscales. They found negative links between character strengths and engagement in sexual behavior as well as attitudes about drug use and premarital sex. These findings suggest that character strengths may be related to decisions that impact physical and psychological health. Broad conclusions based upon these sorts of studies pertaining to the aims of this project are speculative at best, because the studies did not directly examine the hostility-health link, nor did they examine the entire range of character strengths from the VIA measure.

Despite a dearth in research directly investigating the role of character strengths in the hostility-health link, character strengths have been indirectly linked to hostility. MacDonald, Bore, and Munro (2008) studied the relations between character strengths and the Big Five personality traits: Conscientiousness, Agreeableness, Neuroticism, Openness to Experiences, and Extraversion. Neuroticism has been closely linked to hostility, such that, chronic hostility and neuroticism are two of the best predictors of poor health (Smith, 2006). MacDonald et al. (2008) reported that Neuroticism was negatively correlated with multiple character strengths (i.e., Citizenship, Love, Hope, Humor, Zest, and Leadership), and additional research has negatively linked Neuroticism to Forgiveness (Brose, Rye, Lutz-Zois, \& Ross, 2005) and Positive Affect (Thompson et al., 2005). These findings suggest that hostility, like neuroticism, may be negatively associated with character strengths, as measured by the VIA. 


\section{Character Strength Interventions}

Examination of character-strength interventions has received increased attention in recent years. In one such study, Rust, Diessner, and Reade (2009) investigated self-report ratings of life satisfaction after participation in a 12-week character-strengths intervention. Participants completed the VIA and then were divided into a Strengths Only group, Strength and Weakness group, or a control group. The participants in the Strengths Only group $(n=35)$ were asked to engage in behaviors associated with their two most highly rated character strengths. The participants in the Strength and Weakness group $(n=41)$ were asked to engage in behaviors associated with their highest and lowest rated strengths. After 12 weeks, both intervention groups reported comparable increases in life satisfaction, whereas the control group reported a decrease in life satisfaction. The authors concluded that character-strength interventions may positively impact life satisfaction.

Additionally, Otake, Shimai, Tanaka-Matsumi, Otsui, and Frederickson (2006) studied the effectiveness of a character strengths intervention on reports of subjective happiness. Female Japanese undergraduate students were divided into an intervention $(\mathrm{N}=71)$ or a control $(\mathrm{N}=48)$ group. All participants were asked to complete a measure of subjective happiness one month prior to and one month after the intervention. The participants assigned to the intervention group were asked to record the number of kind acts they engaged in for one week. At baseline, the groups did not differ in subjective happiness. At the one-month follow-up, the intervention group endorsed greater subjective happiness in comparison to the control group. The authors also examined differences within the intervention group. Intervention participants who endorsed engaging in more kind acts reported a greater increase in subjective happiness than the intervention participants who reported engaging in fewer kind acts. These findings suggest that 
interventions designed to increase engagement in character strengths may positively impact subjective well-being.

Furthermore, Seligman, Steen, Park, and Peterson (2005) divided 577 participants (58\% female) into an intervention or control group. The five intervention groups were designed to increase subjective happiness. One intervention related to increasing gratitude, two pertained to improving self-awareness, and the remaining two interventions related to using character strengths. Each intervention lasted for one week and was composed solely of on-line exercises. Over the next six months, happiness and depression were periodically measured. The participants in the intervention group who were asked to use their character strengths each day in novel ways reported higher levels of happiness and lower levels of depressive symptoms six months after completing the intervention in comparison to the other intervention groups and control group. Notably, this effect was mediated by adherence to the task during the intervention and continued practice of the task after the completion of the intervention.

Lastly, Proctor, Maltby, and Linley (2011) examined the relations between use of one’s character strengths and subjective well-being and health. A sample of 135 undergraduate students (75.6\% female) was presented with a list consisting of the name and a brief definition of each of Peterson and Seligman's character strengths. They were asked to select the five character strengths that most closely represented them. The strengths most often selected were Social Intelligence, Judgment, Humor, Kindness, and Love. The strengths selected least often were Perseverance, Wisdom, Self-regulation, Religiousness, and Leadership. Participants then completed multiple psychological measures, including a 14-item questionnaire that assessed use of strengths across multiple settings. Character strength use was associated with subjective wellbeing but not with mental or physical health. These findings suggest a positive relation between 
subjective character strength use and well-being. However, participants did not actually complete the VIA and the relation between character strength and health was not directly examined.

Despite the rise in interest in character strength and related interventions, it is currently unknown if character strengths are in any way associated with hostility or its linkage to health outcomes. Character strengths have been positively linked to greater happiness (Peterson, Ruch, Beerman, Park, \& Seligman, 2007) and predictive of life satisfaction (Lounsbury, Fisher, Levy, \& Welsh, 2009), whereas life satisfaction and hostility have been negatively linked (HamdanMansour, 2010). These findings indirectly suggest that hostility may be negatively linked to character strengths, which in turn are positively associated with psychological and physical health. One purpose of this study, then, was to explore the relation of character strength to hostility and health.

\section{Chapter 3: Significance of the Study}

It is vital to understand why hostile individuals experience poor health outcomes, so interventions designed to alleviate these psychological and physical health problems can be developed. Current interventions based on Smith’s models aim to encourage hostile individuals to engage in healthier behaviors (Health Behavior Model), develop trusting relationships with others (Psychosocial Vulnerability Model), or reduce physiological reactivity to stress (Psychophysiological Reactivity Model). Unfortunately, development and testing of these interventions are not supported because none of these models has emerged as the prevailing description of the mechanism linking hostility with health. Furthermore, these interventions may be perceived aversively by hostile individuals because they focus on altering behaviors (e.g., reducing reactivity, increasing socially supportive relationships) that may be difficult to change. 
Presumably, interventions based on increasing behaviors associated with character strengths may be more tolerable. Teaching hostile individuals to engage in activities they enjoy will likely result in greater adherence than attempting to change longstanding patterns of behavior. For example, through this approach, hostile individuals who report high scores on the dimension of Love of Learning would be encouraged to engage in more activities related to this character strength (e.g., reading a new book, taking a college course). Therefore, rather than stopping maladaptive behaviors or adding new behaviors that may be aversive to learn (e.g., relaxation, trusting others), interventions would focus on building identified character strengths and engaging in these presumably enjoyable activities. Through knowledge gained from this study, we learned whether there was any basis to consider the importance of evaluating character strengths among hostile persons and whether subsequent work to incorporate them into therapeutic trials was warranted.

\section{Chapter 4: Specific Aims and Research Hypotheses}

Smith and Mackenzie (2006) suggested that while the hostility-health link has been widely supported in the literature, formal mediational analyses to explain this link have yet to be conducted. They go on to point out that the models that Smith proposed fourteen years earlier, had yet to be thoroughly investigated. Therefore, the aim of the study presented here was to further investigate a few of Smith's models of hostility and health in addition to examining the role of character strengths and virtuous behaviors in explaining the hostility-health relation. To these ends, the study employs analysis of data to conduct formal tests of mediation on the Psychosocial Vulnerability and Health Behavior Models as well as hierarchical regressions to test hostility, social support, health behavior, character strength, and virtuous behavior as predictors of physical and psychological health. Data for examining the Psychophysiological 
Reactivity, Transactional, and Constitutional Models of hostility were not collected and were not examined. Specific aims of the current study were as follows:

Specific aim 1. To examine if the Psychosocial Vulnerability and Health Behavior Models explain the hostility-health link for both psychological and physical health. Based upon previous empirical work (Grothe et al., 2008) and the findings of the secondary data analysis reported above, it was expected that social support would partially mediate the relation between hostility and health, and health behavior would not.

Specific aim 2. To explore the relations of character strength and virtuous behavior to hostility and psychological and physical health. Because no previous empirical work has addressed this aim, the expectation that character strength might be related to hostility and psychological and physical health is based solely on indirect evidence from a few studies in which hostility has been associated with fewer character strengths (Brose et al., 2005; MacDonald et al., 2008; Thompson et al., 2005) and that character strengths have been associated with improved psychological and physical health status (Huta \& Hawley, 2008; Peterson et al., 2007).

\section{Chapter 5: Method}

\section{Participant Characteristics}

Of the 717 young adults recruited to participate in the study, data from 28 participants were excluded from the analyses based on evidence of a response set (e.g., they provided the same response to all items or systematically alternated responses to items) or they were outliers. See Figure 1 for participant flow chart. The average age of the remaining 689 participants (69.4\% female) was 19.89 years old $(S D=1.77)$. A majority of the participants identified 
themselves as Caucasian (88.8\%), single (96.1\%), and students (80.7\%). T-tests were conducted comparing the responses of males and females on self-reports of psychological health, physical health, hostility, health behavior, character strength, and virtuous behavior (see Table 2). Notably, females reported engaging in significantly more virtuous behaviors, being less hostile, and experiencing more physical health symptoms than males.

\section{Self-Report Measures}

Demographic variables. The demographic questionnaire (Appendix A) included background and demographic items, including age, sex, ethnicity, highest level of education, and occupation.

Hostility. Hostility was measured using the Cook-Medley Hostility Scale (Cook \& Medley, 1954; Appendix B), an instrument derived from the Minnesota Multiphasic Personality Inventory. Included in the inventory are 50 questions assessing cynicism, mistrust of others, and suspicion of others. The measure traditionally has a true-false format, but a 4-point Likert-type scale (1 = rarely, 4 = all the time) was used to assess levels of hostility during data collection. Cook and Medley (1954) reported that the scale had an internal consistency of .86, a feature confirmed by Smith and Frohm (1985), who reported that the scale had a Cronbach's alpha of .80. In the present study, a similar Cronbach's alpha was observed, $\alpha=.90$. Additionally, a .85 test-retest correlation at one year (Barefoot, Dahlstrom, \& Williams, 1983) and a .84 test-retest correlation at four years (Shekelle, Gale, Ostfeld, \& Paul, 1983) have been reported. These findings suggest that the Cook-Medley Hostility Scale assesses stable trait hostility over time.

Physical health. The Pennebaker Inventory of Limbic Languidness (PILL) was used to measure physical symptoms (Pennebaker, 1982; Appendix C). Participants were asked to rate 
how often they experienced 54 common physical symptoms (e.g. coughing or headaches) on a 6point Likert-type scale ( 0 = not at all, 5 = more than once per day), with higher scores indicating more physical health symptoms. The original PILL did not instruct participants to assess experience of physical symptoms within a specific time period, so based on suggestions by Rauch et al. (2009), a time period of one month was used. This modified PILL has high internal consistency $(\alpha=.94)$ and test-retest reliability $(r=.83)$ over a 2-month period (Rauch et al., 2009). The Cronbach’s alpha in the present study was .94, suggesting good internal consistency validity. Furthermore, the PILL has been shown to be a reliable measure of physical symptoms in college students (Muris \& van Zuuren, 1992; Thompson, Waltz, Croyle, \& Pepper, 2007).

Psychological health. Psychological health was measured using the Brief Symptom Inventory (BSI; Derogatis \& Melisaratos, 1983; Appendix D). Participants were asked to rate how often they experienced 53 psychological symptoms over the past seven days using a 5-point Likert scale $(0=$ not at all, $4=$ extremely $)$. The measure is composed of nine subscales: Somatization, Obsession-Compulsion, Interpersonal Sensitivity, Depression, Anxiety, Hostility, Phobic Anxiety, Paranoid Ideation and Psychoticism. Internal consistency across the subscales ranges from .70 to .89, and 2-week test-retest reliabilities range from .68 to .91 (Derogatis \& Melisaratos, 1983). The Global Symptom Index (GSI) represents total psychological symptoms experienced, with higher numbers indicating more symptoms; it is calculated by summing all items. The GSI has good reliability $(\alpha=.97)$. In the present study, a similar Cronbach's alpha was observed, $\alpha=.96$, suggesting that the GSI is a reliable measure of total psychological symptoms.

Social support. Social support was measured using the Interpersonal Support Evaluation List (ISEL; Cohen, Mermelstein, Kamarck, \& Hoberman, 1985; Appendix E). The ISEL has a 
true-false format and is composed of 40 statements about perceptions of social support availability. The questions are divided into four subscales: Self-Esteem Social Support, Belongingness Social Support, Tangible Social Support, and Appraisal Social Support. Cronbach’s alphas for these subscales reportedly range from .62 to .84 (Cohen et al., 1985). For the total ISEL social support score (acquired by summing the total of all four subtests), test-retest reliability over a two-day period was .87 (Bates \& Toro, 1999). In the present study, Cronbach’s alpha of the total ISEL social support score was only .41. Additional analyses were conducted to identify an alternate configuration of the ISEL with good internal consistency that could be used in the study analyses.

The first analyses examined the Cronbach's alpha values of the four subscales of the ISEL to determine if the subscales, rather than a composite social support value, demonstrated better internal consistency. However, the alpha values for the subscales were also low (Appraisal Subscale $=.04$, Tangible Subscale $=.11$, Self-esteem Subscale $=-.33$, Belonging Subscale $=$ .07), demonstrating poor internal consistency. Next, an exploratory factor analysis was conducted to investigate the factor structure of the ISEL and to determine if the scale had a stable factor structure. A nine-factor structure resulted, and six items exhibited loading values less than .45. The Cronbach's alpha of the remaining 34 items was calculated $(\alpha=.36)$ to determine if the remaining items composed a more internally consistent subscale. However, the low alpha value suggests that this configuration of the ISEL also did not produce good internal consistency and should not be used in the study analyses.

A second factor analysis was conducted to determine if the 40 ISEL items could be analyzed as a composite value. Forcing items into a one-factor solution, 14 items demonstrated loading values below .45. The alpha value of the remaining 26 items was examined $(\alpha=.23)$, 
again suggesting poor internal consistency of this configuration of the ISEL. Lastly, the mean values of each item were examined to identify items with limited response variance. Items where 90+ percent of the participants responded in the same manner were identified. Eleven items exhibited little response variance. The Cronbach’s alpha of the remaining 29 items was .54, demonstrating an improvement but still insufficient internal consistency. No variation of the ISEL with good internal consistency was found. As a result, the measure was not included in the study analyses and the Psychosocial Vulnerability Model could not be tested in the present study.

Health behavior. Health behavior was assessed using the Healthy Lifestyle Questionnaire (HLQ), which is a 30-item self-report questionnaire (Appendix F). The measure includes 11 subscales assessing general health behavior including: Physical Activity, Nutrition, Managing Stress, Avoiding Destructive Habits, Practicing Safe Sex, Adopting Safety Habits, Knowing First Aid, Personal Health Habits, Using Medical Advice, Being an Informed Consumer, and Protecting the Environment. All items are rated using a yes/no format, and a total Health Behavior score was calculated by summing the number of “yes” answers (higher scores indicated engagement in more healthy behavior in comparison to lower scores). This measure has not been formally validated or normed; however, the items have face validity, and some research (e.g., Behavioral Risk Factor Surveillance System; BRFSS) uses similar questions when measuring engagement in health behavior (CDC, 2007). In the present study, the Cronbach’s alpha of the total Health Behavior score was .81, suggesting that the total HLQ is an internally consistent measure of health behavior.

Character strength. All 24 of Peterson and Seligman's character strengths are measured by the VIA Inventory of Strengths (VIA; Appendix G). It is a 240-item measure that includes 10 items assessing cognition, emotion, and behavior associated with each character strength. 
Participants were asked how much each item described them using a 5-point Likert-type scale (1 = very much unlike me, 5 = very much like me). It took approximately 30-40 minutes to complete the measure. Scores can range from 10 to 50 for each strength, with higher scores indicating greater endorsement of the character strength. Item examples include "I always let bygones be bygones” (Forgiveness) and "I find the world a very interesting place” (Curiosity). Park et al. (2004) and Peterson et al. (2006a) reported Cronbach’s alphas were above .70 for all subscales, and test-retest correlations over four months was .70, indicating good test-retest reliability. For the present study, Cronbach's alphas for the individual subscales were not made available by the VIA Institute, so they cannot be reported here. Furthermore, based upon preliminary data analyses described in Appendix $\mathrm{H}$, a single, aggregate VIA score was used in all relevant primary analyses. The Cronbach’s alpha for the Total Character Strengths score was calculated using the mean response for each of the 24 subscale scores reported to us by the VIA Institute rather than the individual item responses because they were not provided. The Total Character Strength alpha observed in this study was .97, indicating that the 24 character strengths are highly intercorrelated with one another and that they may function best as a single, aggregate variable.

Virtuous behavior. The VIA includes items that assess cognitions, behaviors, and emotions. Due to restrictions put in place by the VIA Institute, it was not possible to access individual items for each subscale. As a result, the behavioral items could not be separated from the non-behavioral items of the VIA. Therefore, the Virtuous Behavior Scale (VBS) was created, using solely behavioral items for the present study. The 48-items of the VBS are based on the character strengths conceptualized by Peterson and Seligman (Appendix H). Two items were created based on each of Peterson and Seligman’s character strengths. Note, to distinguish 
between the scales, the term character strength will be used when referring to the VIA and the term virtuous behavior will be used when referring to the VBS.

Participants were asked to rate how often they engaged in each virtuous behavior using a 5-point Likert-type scale (1 = never, 5 = all of the time). Item examples include "When I feel like someone has wronged me, I talk to him/her to clear the air.” (Forgiveness) and "When I receive mail, I refrain from opening it for long periods of time.” (Curiosity--Reverse Coded). An aggregate score was used to create a total Virtuous Behavior score. In the present study, the Cronbach’s alpha of the total Virtuous Behavior Scale was .85, suggesting good internal consistency.

\section{Procedure}

Participants completed the measures using an on-line survey after being recruited through psychology courses. They accessed online research systems through the SONA Systems and VIA Institute's websites. Participants were presented with an informed consent form that outlined the purpose of the study through SONA Systems research participation portal, and had the opportunity to discontinue participation at any time. For those who agreed to consent, they were presented with all of the above mentioned measures (except the VIA), with the opportunity to decline answering all questions that they did not wish to answer. Participants completed the Demographics Questionnaire first, so they began by completing the least invasive questions. Participants then completed the Cook-Medley Hostility Scale, the Pennebaker Inventory of Limbic Languidness, Brief Symptom Inventory, Interpersonal Support Evaluation List, Healthy Lifestyle Questionnaire, and finally the Virtuous Behavior Scale. 
Participants were then provided with a web address for the VIA website and a password to gain access to the study. After logging into the VIA site and completing a brief demographics section that required provision of a personal email address, participants completed the Values in Action Inventory of Strengths Scale. Participants were presented with ten items on each page and were required to provide a response for each item (non-response was not an option) before receiving the next set of items. After completing the VIA, each participant was shown his or her top five character strengths. By providing an email address, participants had the opportunity to view their results at a later date.

After completion of the SONA portion of the study, respondents automatically received a designated amount of extra credit in their psychology courses. Participants who completed all study questionnaires were given two units of extra credit in their psychology courses; participants who completed the initial questionnaires, but did not complete the VIA, were given one unit of extra credit.

\section{Chapter 6: Data Checking and Reduction}

The extent of missing data was assessed for each of the scales. Missing data was handled by using an individual mean substitution method (Widaman, 2005). Individual mean substitution refers to calculating a mean value of the answered items on a scale, then substituting this mean as the value of the missing items. In the present study, individual mean substitution was used if an individual answered at least $70 \%$ of the items on a scale (i.e. 7 out of 10 questions on a scale). If they answered less than $70 \%$ of the items, their data for the scale was excluded from further analysis. The nature of missing data was also examined. Notably, missing data was relative low for many of the study variables: hostility, physical health, psychological health, health behavior, 
social support, and virtuous behavior. In contrast, the percentage of missing data for character strengths measured via the VIA was nearly fifty percent (see Table 3). This is likely a result of the multi-website procedure used in the study. Participants who completed the VIA were compared to participants who did not complete the VIA (see Table 4). Notably, those who completed the VIA reported engaging in more virtuous behaviors, fewer health behaviors, and being more hostile than the participants who did not complete the VIA. Although these differences were statistically significant, further inspection revealed that the mean differences were quite small, suggesting little clinical or practical differences between these groups. The total study sample of 689 participants was used to examine the first hypothesis. Because only about half of the study sample completed the VIA, a smaller sample of 337 participants was used to test the second hypothesis pertaining to character strengths.

\section{Data Distribution}

We examined data for evidence of univariate and multivariate outliers; their data were then excluded from analyses (see Figure 1). We also examined each variable for evidence of skew and kurtosis. Skew and kurtosis values were divided by their respective standard error values to calculate z-scores (see Table 3). Values that exceeded three standard deviations from the mean were considered to be non-normally distributed. Both total scores from the PILL and BSI revealed significant positive skew and kurtosis, suggesting the need for data transformation. A normal distribution was approximated for the PILL using a log linear transformation. However, neither a log nor square root transformation resulted in a normal distribution for the BSI. The square root transformation lessened but did not eliminate the skew, and the log transformation resulted in a severe negative skew. Consequently, the square root transformed 
BSI was used in the primary analyses. Distributions for the CM, HLQ, VBS, and VIA did not exhibit problems related to skew or kurtosis and approximated the normal distribution.

\section{Examination of Potential Covariates}

All of the study variables as well as multiple demographic (e.g., age, gender) variables were examined to identify potential covariates to consider when conducting the regression analyses to test the primary hypotheses. No evidence of multicollinearity was found across study variables, verifying that all variables could be incorporated into the same analysis.

\section{Primary Study Analyses}

The first aim of study was to examine two previously proposed mediational models of the hostility-health link. Because of questionable reliability of the measure of social support (i.e., ISEL), only one mediational model was tested. The relation of health behavior in explaining the hostility-health outcome measure associations were tested using a Baron and Kenny (1986) test of mediation. First, a Pearson correlation coefficient between hostility and both outcome variables (e.g., psychological health and physical health) was calculated to demonstrate the overall association between hostility and health. Next, a correlation coefficient between hostility and the potential mediator variable (e.g., health behavior) was calculated as well as the correlation coefficients between the potential mediator variable and the outcome variables. Finally, 4-step hierarchical regressions were conducted to test for mediation. In Step 1, gender was entered into the equation. In Step 2, hostility was entered to confirm the association between hostility and health outcomes. In Step 3, the potential mediator variable was added to the equation (e.g., health behavior) to examine whether it explained any unique variance to the hostility-health linkage observed in Step 2. Lastly, in Step 4, the interaction variables, hostility- 
by-gender and health behavior-by-gender, were added to the model to test for gender effects. If a significant amount of variance was explained by the potential mediating variable in Step 3, a Sobel test was conducted to determine whether the variable functioned as a significant total or partial mediator. These steps were conducted separately for global measures of physical and psychological health.

The data analytic plan to address the second aim of the study used hierarchical regression analyses. In Step 1, gender was entered into the equation. Hostility was added in Step 2, and health behavior was added in Step 3. In Step 4, the interaction variables, hostility-by-gender and health behavior-by-gender, were added to the model. Character strength and virtuous behavior were added in Step 5. Finally, the character strength-by-gender and virtuous behavior-by-gender interaction terms were added to the model in Step 6.

\section{Chapter 7: Results}

The intercorrelations between the study variables are presented in Table 5. Congruent with previous research, hostility and physical health symptoms were positively correlated, $r$ $(672)=.32, p<.001$, as were hostility and psychological health symptoms, $r(672)=.51, p<$ .001. Furthermore, psychological and physical health symptoms were positively correlated with one another, $r(672)=.66, p<.001$. These findings indicated that hostility was related to both physical and psychological health symptoms.

\section{Aim 1: Mediational Models of the Hostility-Health Relation}

Health behavior was examined as a potential mediator of the hostility-health link because it met Baron and Kenny mediation criteria. Social support was not examined as a potential 
mediator due to poor internal consistency of the ISEL. As a result, the Psychosocial Vulnerability Model could not be examined in the present study.

\section{Health Behavior and Physical Health}

Health behavior was investigated as a potential mediator of the relation between hostility and physical health (see Table 6). Gender significantly predicted physical health, $F(1,668)=$ 15.79, MSE = .162, $p<.001, R^{2}=.023$, and it remained a significant predictor of physical health after hostility was added to the model, $F(2,667)=59.02, M S E=.530, p<.001, R^{2}=.150$. Over and above gender and hostility, health behavior was also significantly associated with physical health, $F(3,666)=48.85, M S E=.424, p<.001, R^{2}=.180$. The interaction terms (hostility-bygender and health behavior-by gender) did not contribute significantly to the model, $F(5,664)=$ 20.52, $M S E=.256, p<.001, R^{2}=.182$. Because health behavior was significant, over and above gender and hostility, a Sobel test was used to determine if health behavior was a significant partial mediator of the link between hostility and physical health. The test was significant $(p<$ .001), suggesting that health behavior was a significant partial mediator of the relation between hostility and physical health. However, it should be noted that most of the variance of physical health was accounted for by hostility; health behavior itself only accounted for a small amount of additional variance in the model.

\section{Health Behavior and Psychological Health}

Health behavior was also investigated as a potential mediator of the relation between hostility and psychological health (see Table 7). Gender did not significant predict psychological health, $F(1,668)=1.35, M S E=.6 .72, p=.246, R^{2}=.002$. After hostility was added to the model, the equation was significant, $F(2,667)=132.58, M S E=473.87, p<.001, R^{2}=.284$. 
Over and above hostility, health behavior was also significantly associated with psychological health, $F(3,666)=120.08, M S E=389.85, p<.001, R^{2}=.351$. The interaction terms, hostilityby-gender and health behavior-by gender, did not contribute significantly to the model, $F$ (5, $664)=72.71, M S E=235.77, p<.001, R^{2}=.354$. A Sobel test was conducted because health behavior was significant predictor of psychological health, over and above gender and hostility. Once again, the test was significant $(p<.001)$, suggesting that health behavior was a significant partial mediator of the relation between hostility and psychological health. It should be noted that most of the variance of psychological health was accounted for by hostility rather than health behavior.

\section{Aim 2: Hierarchical Regressions Predicting Health}

In order to develop and test a more comprehensive predictive model of health using character strength and virtuous behavior, two hierarchical linear regressions were conducted predicting either physical health or psychological health. Gender was entered in Step 1 of the equation, and hostility was entered in Step 2. Health behavior was entered in Step 3 because it was significantly correlated to both physical and psychological health (see Table 5). The interaction terms, hostility-by-gender and health behavior-by-gender, were added in Step 4. Character strength and virtuous behavior were entered in Step 5. By placing these variables in the regression, the relations of personality and behavior to health outcomes were comparable because Peterson and Seligman's conceptualization of character strengths includes components of personality and the conceptualization of virtuous behavior pertains solely to behavior. Finally, the interaction terms, character strength-by-gender and virtuous behavior-by-gender, were added in Step 6 of the model. 


\section{Hierarchical Regression Predicting Physical Health.}

Results from the regression predicting physical health were consistent with the mediational findings (see Table 8). The first model was significant, $F(1,334)=16.81, M S E=$ $.152, p<.001, R^{2}=.048$, suggesting that gender was a significant predictor of physical health. The second model (adding hostility as a predictor) was also significant, $F(2,333)=38.87, M S E$ $=.301, p<.001, R^{2}=.189$, with both hostility and gender being significant predictors. The third model (adding health behavior) was also significant, $F(3,332)=30.35, M S E=.228, p<.001$, $R^{2}=.215$. Gender, hostility, and health behavior were significant predictors. The fourth step (adding the hostility-by-gender and health behavior-by-gender interaction terms) was also significant, $F(5,330)=18.82, M S E=.141, p<.001, R^{2}=.222$. The significant predictors in the model were gender, hostility, and health behavior, but neither interaction term was significant. The equation from Step 5 (adding character strength and virtuous behavior) was also significant, $F(7,328)=13.63, M S E=.102, p<.001, R^{2}=.225$. Again, the significant predictors in the model were gender, hostility, and health behavior but neither interaction term, character strength, nor virtuous behavior, was significant. Finally, the equation from Step 6 (adding the interaction terms character strength-by-gender and virtuous behavior-by-gender) was also significant, $F$ ( 9 , 326) $=10.55, M S E=.080, p<.001, R^{2}=.226$. The significant predictors in the model were gender, hostility, and health behavior but none of the interaction terms, virtuous behavior, or character strength was significant. These results suggest that physical health was consistently predicted by gender, hostility, and health behavior alone.

\section{Hierarchical Regression Predicting Psychological Health.}


Results from the regression predicting psychological health were consistent with the mediational findings (see Table 9). The first model was not significant, $F(1,334)=2.31, M S E=$ 10.83, $p<.129, R^{2}=.004$, suggesting that gender was not a significant predictor of psychological health. The second model (adding hostility as a predictor) was significant, $F$ (2, 333) $=70.26$, MSE $=233.90, p<.001, R^{2}=.297$, with gender and hostility being significant predictors. The third model (adding health behavior) was also significant, $F(3,332)=65.74$, $M S E=195.81, p<.001, R^{2}=.373$. Gender, hostility, and health behavior were significant predictors. The fourth step (adding the hostility-by-gender and health behavior-by-gender interaction terms) was also significant, $F(5,330)=39.32, M S E=117.71, p<.001, R^{2}=.373$. The significant predictors in the model were gender, hostility, and health behavior but neither interaction term was significant. In Step 5 (adding character strength and virtuous behavior), $F$ $(7,328)=31.99, M S E=91.37, p<.001, R^{2}=.406$, the significant predictors included gender, hostility, health behavior, and virtuous behavior, but neither of the interaction terms nor character strength was significant. Finally, in the sixth step (adding the interaction terms character strength-by-gender and virtuous behavior-by-gender), the model was significant, $F$ ( 9 , $326)=25.12, M S E=71.72, p<.001, R^{2}=.409$. The significant predictors in the model were gender, hostility, and virtuous behavior, but none of the interaction terms, hostility, or character strengths was significant. These results suggest that psychological health was consistently predicted by gender, hostility, and virtuous behavior.

Overall, gender and hostility were the most consistent predictors of health symptoms. However, health behavior was a significant predictor of physical health and virtuous behavior was a significant predictor of psychology health. Character strength was not predictive of either health outcomes. Finally, none of the gender interaction terms were significant. 


\section{Hierarchical Regressions Predicting Health Excluding Character Strength}

Character strength was not a significant predictor in either of the regression analyses reported above; however, approximately half of the participants in this study were excluded from these analyses because they did not complete the VIA. Additional hierarchical linear regressions were conducted predicting each health outcome, excluding character strength from the analyses. This allowed for inclusion of the aforementioned missing participants. All other components of the procedure used in the two preceding hierarchical regressions were used in these analyses. Notably, the results from these regressions (see Tables 10 and 11) were similar to the results from the original regression, and as a result, the findings will not be described further.

\section{Chapter 8: Discussion}

The purpose of the present study was to examine two previously proposed mediational models of the hostility-health relation (Health Behavior and Psychosocial Vulnerability Models). In addition, this study sought to provide a better understanding of hostility and health by examining their relations to character strength and virtuous behavior. Furthermore, the degrees to which character strength and virtuous behavior were related to physical and psychological health were also examined.

\section{Hostility and Health}

Like previous empirical work (see Smith, 1992), hostility was significantly correlated with both physical and psychological health in the current study. In this regard, the link between hostility and health was anticipated. Nevertheless, it is important to replicate findings of previous empirical work using the sample of young adults included in this study. It is important to emphasize that the relation between hostility and health was apparent for both physical and 
psychological health outcomes. Being hostile has significant costs pertaining to overall health maintenance and wellness. In contrast to previous empirical studies, the current study measured physical health using the PILL, and by so doing, has demonstrated its utility for measuring physical health in future examinations of hostility-health relations.

Despite decades of research, the mechanism of how hostile beliefs are linked to poorer health outcomes is still unknown. In 1992, Smith proposed five mediational models to explain why hostile persons experience poorer health outcomes than non-hostile persons. For decades, research has examined these models; however, few of these studies actually test for mediation and the findings are largely inconsistent. One purpose of the present study was to examine both the Health Behavior Model and the Psychosocial Vulnerability Model in explaining the hostilityhealth associations; however, due to scale limitations associated with the measurement of social support, only the Health Behavior Model could be examined in the present study.

\section{Health Behavior Mediational Model}

Based on findings from Goulet and Larkin (2011), health behavior was neither hypothesized to fully nor partially mediate the hostility-health relation. In the present study, health behavior was negatively correlated with both physical and psychological health, suggesting that engagement in fewer health behaviors was associated with reports of more health symptoms. In contrast to expectations, health behavior partially mediated the relations between hostility and both physical and psychological health. Although it was not anticipated that health behavior would partially mediate either hostility-health relation, this finding is consistent with some previous empirical work (e.g., Miller et al., 1995). These results indicate that hostile persons who report engaging in more health behaviors may be less likely to experience increased 
presence of physical and psychological health symptoms. This finding may offer an avenue into improving the quality of health among hostile individuals, specifically through the prevention of the development of a variety of health conditions.

It is also noteworthy that these findings were demonstrated in a population of young adults. Health differences were already evident among higher and lower hostile participants, despite the typically low level of health symptoms observed in this age group. As a result, adolescence or young adulthood may then be the ideal time to intervene with hostile individuals to establish good health behaviors early on, which may attenuate the progression of health conditions in the future. Therefore, interventions that promote engagement in a number of health behaviors (e.g., physical activity, proper nutrition, stress management) may result in improvement in health symptoms for hostile persons. It is logical that engagement in better health behaviors would be linked to fewer health symptoms for hostile persons because many of these health behaviors are known to be associated with improved health outcomes for people in general. However, encouragement to engage in these behaviors may be especially important for hostile individuals, who are suspicious of others and their intentions, and as a result, may be less likely to seek out help from others to manage stress, to acquire information about proper nutrition, etc. As a whole, these findings provide additional support for research that has supported the Health Behavior Model.

Despite these findings, it should be noted that health behavior accounted for only a small amount of unique variance over and above hostility when predicting physical health. This indicates that hostility researchers should investigate other potential mediators to better understand why hostile persons experience poorer physical and psychological health outcomes 
than their less hostile peers. This research would also offer additional insight into how to intervene effectively to improve health outcomes for this population.

Notably, health behavior emerged as a significant partial mediator in the current study but was not a significant mediator in the preliminary study (Goulet \& Larkin, 2011). This difference may be due to an improvement in the assessment of health behavior. In Goulet and Larkin (2011), health behavior was measured using multiple health-related questions on a demographic questionnaire pertaining to cigarette use, alcohol and caffeine consumption, aerobic exercise, and physical activity. None of the examined health behaviors significantly mediated the hostilityhealth link. In the present study, a formal and more comprehensive measure of health behavior was used. The HLQ examines eleven different health behavior domains including health behaviors similar to those examined by Goulet and Larkin as well as a number of other health behaviors, including managing stress, adopting safety habits, practicing safe sex, and using medical advice. In the current study, health behavior was a significant partial mediator for psychological and physical health. It also contributed unique variance over and above hostility when predicting both health variables. The more comprehensive examination of health behavior used in the present study may have resulted in the significant health behavior findings. Even though the psychometrics of the HLQ have yet to be formally analyzed, results of the current study reveal that it has promise. Recalling that the HLQ demonstrated good internal consistency $(\alpha=.85)$ in this study, it appears that it might well serve as a reliable measure of health behavior for future work in this and related areas.

\section{Relations of Character Strength and Virtuous Behavior to Health}


Research has explored the relations of character strengths to life satisfaction, positive affect, self-esteem, and happiness (e.g., Peterson \& Seligman, 2004); however, these studies have not directly examined if character strengths are related to hostility or health. Results of this study revealed that both character strength and virtuous behavior were negatively correlated with the other study variables, including hostility and the presence of physical and psychological health symptoms (see Table 5). As such, individuals with the greatest character strengths and the most engagement in virtuous behaviors reported less hostility and fewer health problems than persons with lesser character strengths and low virtuous behavior engagement. From these correlational analyses, it is unclear if engaging in virtuous behaviors results in an improvement in health symptoms, or if individuals with more health concerns engage in fewer virtuous behaviors due to attitudinal or physical health problems. A longitudinal, cross-sectional study would offer greater insight into the directionality of the relation between these variables.

Based on research demonstrating indirect relations between hostility and character strengths (MacDonald et al., 2008; Brose et al., 2005; Thompson et al., 2005) as well as between character strengths and improved psychological and physical health status (Peterson et al., 2007; Huta \& Hawley, 2008), it was anticipated that character strength and virtuous behavior would significantly predict physical and psychological health. However, regression analyses revealed that character strength did not predict physical or psychological health above and beyond hostility and health behavior. Virtuous behavior, on the other hand, did significantly predict psychological health but not physical health after controlling for variance accounted for by gender, hostility, and health behavior. It is unclear why virtuous behavior but not character strength was related to health; however, this finding indicates that specific engagement in positive behaviors rather than the more diffuse, and perhaps more difficult to measure, 
components of personality may be a better predictor of psychological health. Overall, these findings suggest that Peterson and Seligman's conceptualization of character strengths likely do not broaden our understanding of the hostility-health relation or health in general. Although previous research has demonstrated positive relations between character strengths and a number of positive states (e.g., happiness), this relation did not extend to health symptoms in young adults used in this study after controlling for gender, hostility, and health behavior.

It is noteworthy that virtuous behavior accounted for unique variance in predicting psychological health after controlling for hostility and health behavior engagement because this finding is indirectly consistent with past research. Improvements in life satisfaction (Rust et al., 2009) and subjective happiness (Otake et al., 2006) as well as reductions of depressive symptoms (Seligman et al., 2005) after participation in a character strength intervention have been reported. These interventions often require participants to engage in behaviors associated with character strengths, which is essentially what the VBS measures because it is composed solely of behavioral items based on Peterson and Seligman’s character strengths. This finding suggests that character strength interventions that require participants to engage in behaviors associated with character strengths (i.e., virtuous behavior) may be linked to improved psychological health outcomes, particularly for hostile individuals.

It is also noteworthy that the same set of independent variables (e.g., gender, hostility) accounted for more variance when predicting psychological health $\left(R^{2}=.226\right)$ than physical health $\left(R^{2}=.409\right)$. This may due to a number of reasons, including the possibility that study participants responded in a socially desirable manner. Because social desirability was not assessed in the current study, this possibility cannot be examined. Alternatively, one of the subscales of the BSI assesses hostility, which appears to overlap with some of the items from the 
Cook-Medley Hostility Scale. This may account for the larger statistical association between hostility and psychological health than between hostility and physical health.

\section{Limitations of the Study}

A major limitation in the present study was the inability to examine the Psychosocial Vulnerability Model due to poor internal consistency of the ISEL. Past research has demonstrated acceptable psychometric properties of the ISEL in student and general population samples (Cohen et al., 1985). The poor internal consistency demonstrated in this study may be due to limited response variation by participants. For $67.5 \%$ of the items on the ISEL, 80+ percent of the participants provided the same response to a given item. This resulted in limited variability in responses to most of the items on the ISEL. This may have affected the scale's internal consistency. Notably, the ISEL successfully measured social support in Goulet and Larkin (2011). However, the mean social support response was lower and more varied in Goulet and Larkin $(M=33.73, S D=5.67)$ than in the present study $(M=60.82, S D=2.05)$. It should be noted that the sample of the prior study consisted mostly of men, and the sample of the current study consisted predominantly of women. Given that women typically report more social support than men, the difference in sex distributions in study samples may account for the differential utility of the ISEL in the two studies. Regardless, due to the questionable psychometric characteristics of the ISEL, the Psychosocial Vulnerability hypothesis could not be examined in this study.

An additional study limitation related to sample homogeneity. A majority of the participants identified themselves as female and Caucasian and all were undergraduate students recruited from a single geographic location, which limits the ability to make inferences about the 
generalizability of the findings. It is unknown if similar results would be found in other samples such as middle-aged or older adults.

In the present study, there were also multiple concerns pertaining to acquisition of the VIA and use of this measure as a research tool. The VIA Institute did not permit use of the VIA scale on the SONA Systems. As a result, participants were required to visit the VIA website to complete the VIA after they had completed the other study measures on SONA. This additional step was likely responsible for the overall 50\% participant attrition rate observed in the study. It is notable that the study was conducted between November and February, falling across the end of the fall semester and beginning of the spring semester. Attrition rates were higher in the fall semester than the spring semester. This could have been due to a number of factors. For example, participants who completed the study in the spring may have been more driven and taken more initiative than the participants who completed the study in the fall semester because they completed the study early on the semester, rather than waiting until the last few weeks of class. Additionally, fewer participants did not complete both portions of the study during the spring semester than the fall semester. Alternatively, the spring semester participants could have been more virtuous than the fall semester participants; thus, they were more likely to complete both portions of the study to earn the full extra credit.

Other ethical considerations concerning participant requirements and procedures in completing the VIA were raised. Specifically, participants were required to provide a personal email address as they logged onto the VIA website. Participants were also required to respond to each item because an option of non-response was not provided. The Institute also did not provide the researcher access to the individual items on the VIA. This restriction limited the type of analyses and psychometric testing that could be conducted on the VIA by the researcher. 
Furthermore, Cronbach's alphas of the individual subscales of the VIA were requested by the researcher, but were not provided by the Institute. As a result, they were not reported in the present study and were not available for examination. Lastly, because the VIA data were collected on the Institute's research system, additional steps were required for the researcher to obtain the data. However, it should be noted that the Institute staff were helpful and responsive to the researcher's questions and needs throughout the entirety of the present study.

\section{Clinical Implications}

The results of the present study may have some limited clinical utility. The findings indicate that hostile persons report experiencing more unfavorable symptoms of physical and psychological health. Because health behavior emerged as a partial mediator of several of the analyses conducted in this study, engagement in health behaviors may be associated with improved health outcomes for hostile persons. However, the small amount of unique variance accounted for by health behavior over and above gender and hostility indicates that other variables should be examined to broaden our understanding of the relation between hostility and health. Additionally, engagement in virtuous behaviors is associated with psychological health, over and above gender and hostility. The results from this study indicate that clinical interventions designed to improve health outcomes for hostile persons would benefit from incorporating a treatment component designed to encourage greater engagement in health behaviors and virtuous behaviors. However, it must be noted that these interventions should solely focus on health behaviors and virtuous behaviors because they contributed only a small amount of unique variance when predicting health. As a result, additional research is needed to identify other factors that may result in the development of interventions that more significantly improve health outcomes for hostile individuals. Additionally, as noted above, adolescence or 
young adulthood may be opportune ages to intervene for hostile individuals as individuals in these age groups are just beginning to develop health habits.

\section{Future Directions and Conclusion}

The present study investigated a previously proposed mediational model of the hostilityhealth relation and explored the relations of character strength and virtuous behavior to hostility and health. These results provide additional support for the Health Behavior Model and also suggest engagement in virtuous behavior may contribute significantly to psychological health. This study also provided insight into the comparisons of a personality-based measure and a behavior-based measure of character strengths. It appears that behaviors associated with Peterson and Seligman's character strengths impact some aspects of health when personality traits do not. This study is also the only known study to compare character strengths and hostility and health directly. It is also the only known study to examine sex effects related to hostility and health as well as health effects by testing both physical and psychological health symptoms.

Future studies should examine the Psychosocial Vulnerability Model, which has been understudied and could not be examined in the present study. Researchers should also investigate the role of social support and health behavior in the hostility-health relation in more diverse samples (e.g., age, ethnicity). Overall, the current findings suggest that health behavior interventions for hostile individuals may be a promising avenue in clinical and research fields to improve health outcomes for this population. 


\section{References}

Barefoot, J. C., Dahlstrom, W. G., \& Williams, R. B. (1983). Hostility, coronary heart disease incidence and total mortality: A 25 year follow up study of 255 physicians. Psychosomatic Medicine, 45, 59-63.

Baron, R. M., \& Kenny, D. A. (1986). The moderator-mediator variable distinction in social psychological research: Conceptual, strategic and statistical considerations. Journal of Personality and Social Psychology, 51, 1173-1182.

Bates, D. S., \& Toro, P. A. (1999). Developing measures to assess social support among homeless and poor people. Journal of Community Psychology, 27, 137-156.

Benotsch, E. G., Christensen, A. J., \& McKelvey, L. (1996). Hostility, social support, and ambulatory cardiovascular activity. Journal of Behavioral Medicine, 20, 163-176.

Biswas-Diener, R. (2006). From the equator to the North Pole: A study of character strengths. Journal of Happiness Studies, 7, 293-310.

Brondolo, E., Grantham, K., Karlin, W., Taravella, J., Mencía-Ripley, A., Schwartz, J., et al. (2009). Trait hostility and ambulatory blood pressure among traffic enforcement agents: The effects of stressful social interactions. Journal of Occupational Health Psychology, $14,110-121$.

Brondolo, E., Rieppi, R., Erickson, S. A., Bagiella, E., Shapiro, P. A., McKinley, P., et al. (2003). Hostility, interpersonal interactions, and ambulatory blood pressure. Psychosomatic Medicine, 65, 1003-1011.

Brose, L. A., Rye, M. A., Lutz-Zois, C., \& Ross, S. R. (2005). Forgiveness and personality traits. Personality and Individual Differences, 39, 35-46.

Centers for Disease Control and Prevention. National Center for Injury Prevention and Control. 
(2007). Behavioral Risk Facto Surveillance System. Trends Data. Retrieved from http://apps.nccd.cdc.gov/brfss/

Christensen, A. J., \& Smith, T. W. (1993). Cynical hostility and cardiovascular reactivity during self-disclosure. Psychosomatic Medicine, 55, 193-202.

Christensen, U., Lund, R., Damsgaard, M. T., Holstein, B. E., Ditlevsen, S., Diderichsen, F., et al. (2004). Cynical hostility, socioeconomic position, health behaviors, and symptom load: A cross-sectional analysis in a Danish population-based study. Psychosomatic Medicine, 66, 572-577.

Cohen, S., Mermelstein, R., Kamarck, T, \& Hoberman, H. (1985). Measuring the functional components of social support. In I. Sarason and B. Sarason (Eds.), Social support: Theory, research, and applications (pp. 73-94). The Hague, The Netherlands: Martinus Nijhoff.

Cook, W. W., \& Medley, D. M. (1954). Proposed hostility and pharisaic-virtue scales for the MMPI. The Journal of Applied Psychology, 38, 414-418.

Dahl, R. (2006). Sleeplessness and aggression in youth. Journal of Adolescent Health, 38, 641642.

Derogatis, L. R., \& Melisaratos, N. (1983). The Brief Symptom Inventory: An introductory report. Psychological Medicine, 13, 595-605.

Engin, E., Gurkan, A., Dulgerler, S., \& Arabaci, L. B. (2009). University students' suicidal thoughts and influencing factors. Journal of Psychiatric and Mental Health Nursing, 16, 343-354.

Evans, P. D., \& Edgerton, N. (1992). Mood states and minor illness. British Journal of Medical Psychology, 65, 177-186. 
Gidron, Y., Hassid, A., Yisrael, H., \& Biderman, A. (2005). Do psychological factors predict occurrence of influenza-like symptoms in vaccinated elderly residents of a sheltered home? British Journal of Health Psychology, 10, 411-420.

Goulet, C. L. \& Larkin, K. T. (2011). Examination of Mediational Models of the Hostility-Health Link. Poster presentation at $32^{\text {nd }}$ Annual Society of Behavioral Medicine Conference, Washington, D.C.

Grano, N., Vahtera, J., Virtanen, M., Keltikangas-Jarvinen, L., \& Kivimaki, M. (2008). Association of hostility with sleep duration and sleep disturbances in an employee population. International Journal of Behavioral Medicine, 15, 73-80.

Grothe, K. B., Bodenlos, J. S., Whitehead, D., Olivier, J., \& Brantley, P. J. (2008). The psychosocial vulnerability model of hostility as a predictor of coronary heart disease in low-income African Americans. Journal of Clinical Psychology in Medical Settings, 15, 163-169.

Hamdan-Mansour, A. M. (2010). Predictors of hostility among university students in Jordan. Scandinavian Journal of Caring Sciences, 24, 125-130.

Hardy, J. D., \& Smith, T. W. (1988). Cynical hostility and vulnerability to disease: Social support, life stress, and physiological response to conflict. Health Psychology, 7, 447459.

Harris, P. B., \& Houston, J. M. (2010). Recklessness in context: Individual and situational correlates to aggressive driving. Environment and Behavior, 42, 44-60.

Hart, K. E., \& Hope, C. W. (2004). Cynical hostility and the psychosocial vulnerability model of disease risk: Confounding effects of neuroticism (negative affectivity) bias. Personality and Individual Differences, 36, 1571-1582. 
Heckner, M., Chesney, M., Black, G., \& Frautschi, N. (1989). Coronary-prone behaviors in the Western Collaborative Group Study. Psychosomatic Medicine, 50, 153-164.

Heponiemi, T., Elovainio, M., Kivimäki, M., Pulkki, L., Puttonen, S., \& Keltikangas-Järvinen, L. (2006). The longitudinal effects of social support and hostility on depressive tendencies. Social Science \& Medicine, 63, 1374-1382

Hernandez, D. H., Larkin, K. T., \& Whited, M. C. (2009). Cardiovascular response to interpersonal provocation and mental arithmetic among high and low hostile young adult males. Applied Psychophysiology and Biofeedback, 34, 27-35.

Hillbrand, M., Waite, B. M., Rosenstein, M., Harackiewicz, D., Lingswiler, V. M., \& Stehney, M. (2005). Serum cholesterol concentrations and non-physical aggression in healthy adults. Journal of Behavioral Medicine, 28, 295-299.

Huta, V., \& Hawley, L. (2008). Psychological strengths and cognitive vulnerabilities: Are they two ends of the same continuum or do they have independent relationships with wellbeing and ill-being?. Journal of Happiness Studies, 11, 71-93.

Iwata, N. Suzuki, T., Ikeda, M., Kitajima, T., Yamanouchi, Y., Inada, T., et al. (2004). A genome scan for hostility: The national heart, lung, and blood institute family heart study. Molecular Psychiatry, 9, 124-127.

Johnson, M. (2003). The vulnerability status of neuroticism: over-reporting or genuine complaints? Personality and Individual Differences, 35, 877-887.

Kopp, M. S., Stauder, A., Purebl, G., Janszky, I., \& Skrabski, A. (2008). Work stress and mental health in a changing society. European Journal of Public Health, 18, 238-244.

Lazaro, M. L., Valdes, M., Marcos, T., \& Guarch, J. (1993). Borderline hypertension, daily stress and psychological variables. Stress Medicine, 9, 215-220. 
Lee, D. J., Meehan, R. T., Robinson, C., Smith, M. L., \& Mabry, T. R. (1995). Psychosocial correlates of immune responsiveness and illness episodes in US Air Force Academy cadets undergoing Basic Cadet Training. Journal of Psychosomatic Research, 39, 445457.

Leiker, M., \& Hailey, B. J. (1988). A link between hostility and disease: Poor health habits? Behavioral Medicine, 14, 129-133.

Linley, P. A., Maltby, J., Wood, A. M., Joseph, S., Harrington, S., Peterson, C., et al. (2007). Strengths in the United Kingdom: The VIA inventory of strengths. Personality and Individual Differences, 43, 341-351.

Lounsbury, J. W., Fisher, L. A., Levy, J. J., \& Welsh, D. P. (2009). An investigation of character strengths in relation to the academic success of college students. Individual Differences, 7, 52-69.

Ma, M., Kibler, J. L., Dollar, K. M., Sly, K., Samuels, D., White-Benford, M., et al. (2008). The relationship of character strengths to sexual behaviors and related risks among African American adolescents. International Journal of Behavioral Medicine, 15, 319-327.

Macdonald, C., Bore, M., \& Munro, D. (2008). Values in action scale and the Big 5: An empirical indication of structure. Journal of Research in Personality, 4, 787-799.

Maida, D. M, \& Armstrong, L. S. (2005). The Classification of Muscle Dysmorphia. International Journal of Men's Health, 4, 73-91.

Miller, T. Q., Markides, K. S., Chiriboga, D. A., \& Ray, L. A. (1995). A test of the psychosocial vulnerability and health behavior models of hostility: Results from an 11-year follow-up study of Mexican Americans. Psychosomatic Medicine, 57, 572-581.

Miller, T. Q., Smith, T. W., Turner, C. W., Guijarro, M. L., \& Hallet, A. J. (1996). Meta-analytic 
review of research on hostility and physical health. Psychological Bulletin, 119, 322-348.

Muris, P. \& van Zuuren, F. (1992). Monitoring, medical fears, and physical symptoms. British Journal of Clinical Psychology, 31, 360-362.

Otake, K., Shimai, S., Tanaka-Matsumi, J., Otsui, K., \& Frederickson, B. L. (2006). Happy people become happier through kindness: A counting kindnesses intervention. Journal of Happiness Studies, 7, 361-375.

Park, N., Peterson, C., \& Seligman, M. E. P. (2004). Strengths of character and well-being. Journal of Social \& Clinical Psychology, 23, 603-619.

Pennebaker, J. W. (1982). The Psychology of Physical Symptoms. New York: Springer-Verlag. Peterson, C., \& Seligman, M. E. P. (2003). Character strengths before and after September 11. Psychological Science, 14, 381-384.

Peterson, C., \& Seligman, M. E. P. (2004). Values in Action Inventory of Strengths. In Character strengths and virtues: A handbook and classification. Washington, DC: American Psychological Association.

Peterson, C., Park, N., \& Seligman, M. E. P. (2006a). Character strengths in fifty-four nations and the fifty US states. The Journal of Positive Psychology, 1, 118-129.

Peterson, C., Park, N., \& Seligman, M. E. P. (2006b). Greater strengths of character and recovery from illness. The Journal of Positive Psychology, 1, 17-26.

Peterson, C., Park, N., Pole, N., D’Andrea, W., \& Seligman, M. E. P. (2008). Strengths of character and posttraumatic growth. Journal of Traumatic Stress, 21, 214-217.

Peterson, C., Ruch, W., Beerman, U., Park, N., \& Seligman, M. E. P. (2007). Strengths of character, orientations to happiness, and life satisfaction. The Journal of Positive Psychology, 2, 149-156. 
Proctor, C., Maltby, J., \& Linley, P. A. (2011). Strengths use as a predictor of well-being and health-related quality of life. Journal of Happiness Studies, 12, 153-169.

Rauch, S. A. M., Grunfeld, T. E. E., Yadin, E., Cahill, S. P., Hembree, E., \& Foa, E. B. (2009). Changes in reported physical health symptoms and social function with prolonged exposure therapy for chronic posttraumatic stress disorder. Depression and Anxiety, 26, 732-738.

Ruch, W., Proyer, R. T., Harzer, C., Park, N., Peterson, C., \& Seligman, M. E. P. (2010). Values in Action Inventory of Strengths (VIA-IS) adaptation and validation of the German version and the development of a peer-rating form. Journal of Individual Differences, 31, 138-149.

Rust, T., Diessner, R., Reade, L. (2009). Strengths only or strengths and relative weaknesses? A preliminary study. Journal of Psychology, 143, 465-476.

Schwinn, T. M., Schinke, S. P., \& Trent, D. N. (2010). Substance use among late adolescent urban youths: Mental health and gender influences. Addictive Behaviors, 35, 30-34.

Seligman, M. E P, Steen, T., Park, N., \& Peterson, C. (2005). Positive psychology progress: Empirical validation of interventions. American Psychologist, 60, 410-421.

Seligman, M. E. P. \& Park, N. (2004). The Values in Action (VIA) classification of character strengths. Special issue: Positive Psychology, 27, 63-78.

Shekelle, R. B., Gale, M., Ostfeld, A. M., \& Paul, O. (1983). Hostility, risk of coronary heart disease, and mortiality. Psychosomatic Medicine, 45, 109-114.

Shimai, S., Otake, K., Park, N., Peterson, C., \& Seligman, M. E. P. (2006). Convergence of character strengths in American and Japanese young adults. Journal of Happiness Studies, 7, 311-322. 
Shimbo, D., Chaplin, W., Kuruvilla, S., Wasson, L. T., Abraham, D., \& Burg, M. M. (2009). Hostility and platelet reactivity in individuals without a history of cardiovascular disease events. Psychosomatic Medicine, 71, 741-747.

Siegel, J. M., Yancey, A. K., \& McCarthy, W. J. (2000). Overweight and depressive symptoms among African-American women. Preventive Medicine: An International Journal Devoted to Practice and Theory, 31, 232-240.

Singh, K., \& Choubisa, R. (2010). Empirical validation of values in action-inventory of strengths (VIA-IS) in Indian context. Psychological Studies, 55, 151-158.

Smith, T. W. (1992). Hostility and health: Current status of a psychosomatic hypothesis. Health Psychology, 11, 139-150.

Smith, T. W. (2006). Personality as risk and resilience in physical health. Current Directions in Psychological Science, 15, 227-231.

Smith, T. W., \& Mackenzie, J. (2006). Personality and risk of physical illness. Annual Review of Clinical Psychology, 2, 435-467.

Smith. T. W., \& Frohm, K. D. (1985). What's so unhealthy about hostility? Construct validity and psychosocial correlates of the Cook and Medley Ho scale, Health Psychology, 4, 503-520.

Thompson, L., Snyder, C., Hoffman, L., Michael, S., Rusmussen, H. N., Billings, L. S. et al. (2005). Dispositional forgiveness of self, others, and situations. Journal of Personality, 73, 313-359.

Thompson, L., Waltz, J., Croyle, K., \& Pepper, A. (2007). Trait meta-mood and affect as predictors of somatic symptoms and life satisfaction. Personality and Individual Differences, 43, 1785-1795. 
Wasserman, D., Geijer, T., Sokolowski, M., Rozanov, V., \& Wasserman, J. (2008). Genetic variation in the hypothalamic-pituitary-adrenocortical axis regulatory factor, T-box 19, and the angry/hostility personality trait. Genes, Brain \& Behavior, 6, 321-328.

Widaman, K. F. (2006). Missing data: What to do with or without them. Monographs of the Society for Research in Child Development, 71, 42-64.

Williams, R. B. Jr, Barefoot, J. C., \& Shekelle, R. B. (1985). The health consequences of hostility. In Chesney, M. A. \& Rosenman, R. H. (eds.), Anger and hostility in cardiovascular and behavioral disorders. New York.

Williams, R. B., Jr., Haney, T. L., Lee, K. L., Kong, Y., Blumenthal, J., \& Whalen, R. (1980). Type A behavior, hostility, and coronary atherosclerosis. Psychosomatic Medicine, 42, $539-549$. 
Appendix A: Table 1

Character Strengths and Virtues Terms and Definitions.

Virtues and Character strengths Definitions

\section{Wisdom and Knowledge}

Creativity

Curiosity

Judgment

Love of learning

Perspective

\section{Courage}

Bravery

Perspective

Honesty

Vitality

\section{Humanity}

Love

Kindness

Social intelligence

Justice

Citizenship

Fairness

Leadership
Produce original and adaptive ideas/behaviors

Interest in ongoing experience; pursue novelty

Think critically; use good judgment

Pursue positive feelings through acquisition of knowledge

Analyze life in larger terms based on experience

Do the right thing; standing up for justice

Finish tasks despite obstacles

Take responsibility for one’s feelings and actions

Feeling alive; full of zest and enthusiasm

Reciprocated love in romantic and platonic relationships

Tendency to be nice and compassionate

Insight into own and others’ motives

Sense of obligation to a common good beyond oneself

Treat others equally, without bias

Set goals with help of others 


\section{Temperance}

Forgiveness

Pardon others for wrongdoing without exacting revenge

Humility

Quiet about accomplishments; acknowledge mistakes

Prudence

Practical reasoning to effectively achieve long-term goals

Self-regulation

Control own responses to pursue goals

\section{Transcendence}

Appreciation of beauty and

Connect to something larger than oneself

excellence

Gratitude

Thankful when given a gift

Hope

Expect desired events will occur

Humor

Playfulness; produce amusement and positive emotions

Spirituality

Beliefs about a higher purpose, meaning in the universe in

relation to oneself

Table created from information in Peterson \& Seligman’s 2004 book, Character strengths and virtues: A handbook and classification. 
Appendix B: Table 2

T-tests Comparing Study Variables by Participant Sex.

\begin{tabular}{|c|c|c|c|c|c|c|}
\hline & & & $\underline{\mathrm{Me}}$ & D) & & \\
\hline Scale & Males & Females & Males & Females & $t$ & $p$ \\
\hline $\mathrm{CM}$ & 193 & 478 & $\begin{array}{l}106.08 \\
(15.54)\end{array}$ & $\begin{array}{c}98.93 \\
(15.55)\end{array}$ & 5.39 & $<.001$ \\
\hline PILL & 193 & 478 & $\begin{array}{l}104.90 \\
(25.89)\end{array}$ & $\begin{array}{l}113.44 \\
(27.36)\end{array}$ & -3.97 & $<.001$ \\
\hline BSI & 193 & 478 & $\begin{array}{c}33.49 \\
(25.75)\end{array}$ & $\begin{array}{c}36.07 \\
(27.95)\end{array}$ & -1.20 & .23 \\
\hline HLQ & 193 & 477 & $\begin{array}{l}67.87 \\
(8.50)\end{array}$ & $\begin{array}{l}69.07 \\
(7.75)\end{array}$ & -1.77 & .08 \\
\hline VIA & 92 & 244 & $\begin{array}{c}91.36 \\
(10.93)\end{array}$ & $\begin{array}{c}93.63 \\
(10.57)\end{array}$ & -1.75 & .08 \\
\hline VBS & 193 & 478 & $\begin{array}{l}165.23 \\
(16.98)\end{array}$ & $\begin{array}{l}173.36 \\
(17.17)\end{array}$ & -5.57 & $<.001$ \\
\hline
\end{tabular}

Note. $\mathrm{CM}$ = Cook Medley Hostility Scale; PILL = Pennebaker Inventory of Limbic

Languidness; BSI = Brief Symptom Inventory; HLQ = Healthy Lifestyle Questionnaire; VIA = Value in Action Scale; VBS = Virtuous Behaviors Scale 
Appendix C: Table 3

Descriptive and Normality Distribution Information for Study Variables.

\begin{tabular}{|c|c|c|c|c|c|c|c|c|}
\hline \multirow{3}{*}{ Variable } & \multirow{3}{*}{$\mathrm{N}$} & \multirow{3}{*}{$\begin{array}{l}\text { Mean } \\
\text { (SD) }\end{array}$} & \multirow{3}{*}{ Range } & \multicolumn{2}{|c|}{ Pre- } & \multirow{3}{*}{$\begin{array}{c}\text { Transformation } \\
\text { Method }\end{array}$} & \multirow{2}{*}{\multicolumn{2}{|c|}{$\begin{array}{c}\text { Post- } \\
\text { Transformation }\end{array}$}} \\
\hline & & & & \multicolumn{2}{|c|}{ Transformation } & & & \\
\hline & & & & Skew & Kurtosis & & Skew & Kurtosis \\
\hline $\mathrm{CM}$ & 672 & $\begin{array}{l}100.99 \\
(15.86)\end{array}$ & $59-151$ & 1.40 & -2.24 & Normal & - & - \\
\hline PILL & 672 & $\begin{array}{l}110.96 \\
(27.19)\end{array}$ & $54-220$ & 9.81 & 5.84 & Log & 2.55 & 0.63 \\
\hline BSI & 672 & $\begin{array}{c}35.32 \\
(27.32)\end{array}$ & $0-149$ & 12.71 & 6.62 & $\begin{array}{c}\text { Square Root } \\
\text { Log }\end{array}$ & $\begin{array}{r}3.56 \\
-10.13\end{array}$ & $\begin{array}{r}-1.47 \\
6.91\end{array}$ \\
\hline HLQ & 694 & $\begin{array}{l}68.56 \\
(8.18)\end{array}$ & $30-90$ & -2.32 & 1.55 & Normal & --- & --- \\
\hline VIA & 361 & $\begin{array}{r}92.85 \\
(10.69)\end{array}$ & $\begin{array}{l}65.10- \\
118.50\end{array}$ & .70 & -.62 & Normal & --- & --- \\
\hline VBS & 695 & $\begin{array}{l}170.85 \\
(17.76)\end{array}$ & $123-223$ & -.42 & -1.83 & Normal & --- & --- \\
\hline
\end{tabular}

Note. CM = Cook Medley Hostility Scale; PILL = Pennebaker Inventory of Limbic Languidness; BSI = Brief Symptom Inventory; HLQ = Healthy Lifestyle Questionnaire; VIA = Value in Action Scale; VBS = Virtuous Behaviors Scale 
Appendix D: Table 4

T-tests Comparing Study Variables by VIA Completion Status.

\begin{tabular}{lcccccc}
\hline & & \multicolumn{2}{c}{ Mean (SD) } & & \\
Scale & Complete & Incomplete & Complete & Incomplete & $t$ & $p$ \\
\hline CM & 335 & 337 & 102.25 & 99.74 & 2.06 & .04 \\
& & & $(15.78)$ & $(15.87)$ & & \\
PILL & 335 & 337 & 112.39 & 109.52 & 1.17 & .24 \\
& & & $(28.05)$ & $(26.27)$ & & .87 \\
BSI & 335 & 337 & 35.46 & 35.17 & -0.16 & \\
& & & $(27.95)$ & $(26.72)$ & & .005 \\
HLQ & 334 & 337 & 67.85 & 69.59 & -2.84 & \\
& & & $(8.24)$ & $(7.62)$ & & .01 \\
VBS & 335 & 337 & 172.76 & 169.29 & -2.58 & \\
& & & $(17.77)$ & $(17.04)$ & & \\
\hline
\end{tabular}

Note. $\mathrm{CM}=$ Cook Medley Hostility Scale; PILL = Pennebaker Inventory of Limbic

Languidness; BSI = Brief Symptom Inventory; HLQ = Healthy Lifestyle Questionnaire; VIA = Value in Action Scale; VBS = Virtuous Behaviors Scale 
Appendix E: Table 5

Correlations among Measures of Hostility, Physical Health, Psychological Health, Health

Behavior, Character Strength, and Virtuous Behavior.

\begin{tabular}{lcccccc}
\hline & 1 & 2 & 3 & 4 & 5 & 6 \\
\hline 1. CM & & & & & \\
2. PILL & $.32^{* *}$ & & & & & \\
3. BSI & $.51^{* *}$ & $.66^{* *}$ & & & \\
4. HLQ & $-.22^{* *}$ & $-.24^{* *}$ & $-.36^{* *}$ & & \\
5. VIA & $-.31^{* *}$ & $-.18^{*}$ & $-.34^{* *}$ & $.34^{* *}$ & \\
& & & & & \\
$6 . \mathrm{VBS}$ & $-.48^{* *}$ & $-.21^{* *}$ & $-.40^{* *}$ & $.48^{* *}$ & $.63^{* *}$ \\
\hline
\end{tabular}

Note: ${ }^{*} p<.01 ; * * p<.001$

Note. $\mathrm{CM}=$ Cook Medley Hostility Scale; PILL = Pennebaker Inventory of Limbic

Languidness; BSI = Brief Symptom Inventory; HLQ = Healthy Lifestyle Questionnaire; VIA = Value in Action Scale; VBS = Virtuous Behaviors Scale 
Appendix F: Table 6

Mediation of the Hostility-Physical Health Relation.

\begin{tabular}{|c|c|c|c|c|c|}
\hline Variable & $B$ & $S E B$ & $B$ & $t$ & $p$ \\
\hline \multicolumn{6}{|l|}{ Step 1} \\
\hline Gender & .034 & .009 & .152 & 3.96 & $<.001$ \\
\hline \multicolumn{6}{|l|}{ Step 2} \\
\hline Gender & .051 & .008 & .226 & 6.20 & $<.001$ \\
\hline Hostility & .002 & .000 & .365 & 10.00 & $<.001$ \\
\hline \multicolumn{6}{|l|}{ Step 3} \\
\hline Gender & .052 & .008 & .230 & 6.42 & $<.001$ \\
\hline Hostility & .002 & .000 & .326 & 8.88 & $<.001$ \\
\hline Health Behavior & -.002 & .000 & -.178 & -4.94 & $<.001$ \\
\hline \multicolumn{6}{|l|}{ Step 4} \\
\hline Gender & .052 & .008 & .232 & 6.35 & $<.001$ \\
\hline Hostility & .002 & .000 & .321 & 4.70 & $<.001$ \\
\hline Health Behavior & -.003 & .001 & -.234 & -3.73 & $<.001$ \\
\hline Hostility X Gender & $<.001$ & .001 & .007 & .103 & .918 \\
\hline Health Behavior X Gender & .001 & .001 & .069 & 1.09 & .274 \\
\hline
\end{tabular}


Appendix G: Table 7

Mediation of the Hostility-Psychological Health Relation.

\begin{tabular}{|c|c|c|c|c|c|}
\hline Variable & $B$ & $S E B$ & $B$ & $t$ & $p$ \\
\hline \multicolumn{6}{|l|}{ Step 1} \\
\hline Gender & .221 & .190 & .045 & 1.16 & .246 \\
\hline \multicolumn{6}{|l|}{ Step 2} \\
\hline Gender & .767 & .165 & .156 & 4.66 & $<.001$ \\
\hline Hostility & .076 & .005 & .543 & 16.22 & $<.001$ \\
\hline \multicolumn{6}{|l|}{ Step 3} \\
\hline Gender & .798 & .157 & .162 & 5.08 & $<.001$ \\
\hline Hostility & .068 & .005 & .485 & 14.859 & $<.001$ \\
\hline Health Behavior & -.074 & .009 & -.265 & -8.265 & $<.001$ \\
\hline \multicolumn{6}{|l|}{ Step 4} \\
\hline Gender & .766 & .160 & .156 & 4.794 & $<.001$ \\
\hline Hostility & .064 & .009 & .454 & 7.480 & $<.001$ \\
\hline Health Behavior & -.056 & .016 & -.199 & -3.571 & $<.001$ \\
\hline Hostility X Gender & .006 & .010 & .035 & .585 & .558 \\
\hline Health Behavior X Gender & -.027 & .019 & -.080 & -1.435 & .152 \\
\hline
\end{tabular}


Appendix H: Table 8

Hierarchical Regression Predicting Physical Health.

\begin{tabular}{|c|c|c|c|c|c|}
\hline Variable & $B$ & $S E B$ & $B$ & $t$ & $p$ \\
\hline \multicolumn{6}{|l|}{ Step 1} \\
\hline Gender & .048 & .012 & .219 & 4.10 & $<.001$ \\
\hline \multicolumn{6}{|l|}{ Step 2} \\
\hline Gender & .066 & .011 & .301 & 5.97 & $<.001$ \\
\hline Hostility & .002 & .000 & .385 & 7.62 & $<.001$ \\
\hline \multicolumn{6}{|l|}{ Step 3} \\
\hline Gender & .066 & .011 & .304 & 6.10 & $<.001$ \\
\hline Hostility & .002 & .000 & .354 & 6.98 & $<.001$ \\
\hline Health Behavior & -.002 & .001 & -.164 & -3.32 & .001 \\
\hline \multicolumn{6}{|l|}{ Step 4} \\
\hline Gender & .067 & .011 & .305 & 6.10 & $<.001$ \\
\hline Hostility & .003 & .001 & .412 & 4.38 & $<.001$ \\
\hline Health Behavior & -.004 & .001 & -.291 & -3.12 & .002 \\
\hline Hostility X Gender & .000 & .001 & -.054 & -.581 & -.561 \\
\hline Health Behavior X Gender & .002 & .001 & .146 & 1.55 & .122 \\
\hline \multicolumn{6}{|l|}{ Step 5} \\
\hline Gender & .068 & .011 & .312 & 6.16 & $<.001$ \\
\hline Hostility & .002 & .001 & .375 & 3.75 & $<.001$ \\
\hline Health Behavior & -.003 & .001 & -.266 & -2.79 & .006 \\
\hline Hostility X Gender & .000 & .001 & -.046 & -.490 & .625 \\
\hline
\end{tabular}


Mediating the Hostility-Health Link 60

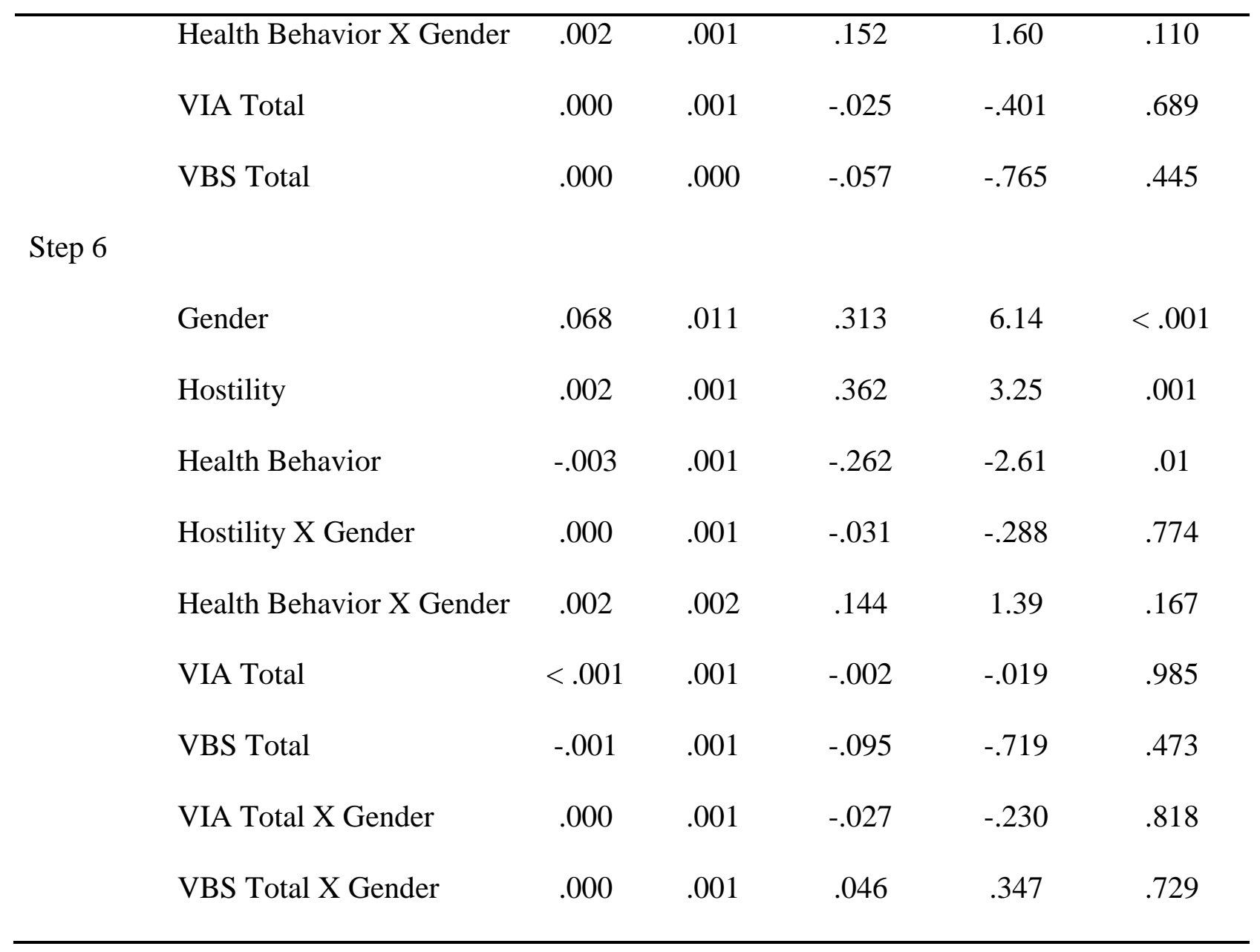


Appendix I: Table 9

Hierarchical Regression Predicting Psychological Health.

\begin{tabular}{|c|c|c|c|c|c|}
\hline Variable & $B$ & $S E B$ & $B$ & $t$ & $p$ \\
\hline \multicolumn{6}{|l|}{ Step 1} \\
\hline Gender & .403 & .265 & .083 & 1.52 & .129 \\
\hline \multicolumn{6}{|l|}{ Step 2} \\
\hline Gender & .977 & .229 & .201 & 4.27 & $<.001$ \\
\hline Hostility & .076 & .006 & .551 & 11.72 & $<.001$ \\
\hline \multicolumn{6}{|l|}{ Step 3} \\
\hline Gender & .997 & .216 & .205 & 4.61 & $<.001$ \\
\hline Hostility & .068 & .006 & .498 & 10.98 & $<.001$ \\
\hline Health Behavior & -.080 & .013 & -.281 & -6.34 & $<.001$ \\
\hline \multicolumn{6}{|l|}{ Step 4} \\
\hline Gender & .962 & .219 & .202 & 4.49 & $<.001$ \\
\hline Hostility & .063 & .012 & .458 & 5.42 & $<.001$ \\
\hline Health Behavior & -.073 & .024 & -.258 & -3.09 & .002 \\
\hline Hostility X Gender & .007 & .014 & .045 & .533 & .594 \\
\hline Health Behavior X Gender & -.007 & .028 & -.022 & -.265 & .792 \\
\hline \multicolumn{6}{|l|}{ Step 5} \\
\hline Gender & 1.08 & .216 & .223 & 5.02 & $<.001$ \\
\hline Hostility & .046 & .012 & .338 & 3.86 & $<.001$ \\
\hline Health Behavior & -.052 & .024 & -.183 & -2.19 & .029 \\
\hline Hostility X Gender & .012 & .014 & .073 & .887 & .376 \\
\hline
\end{tabular}


Mediating the Hostility-Health Link 62

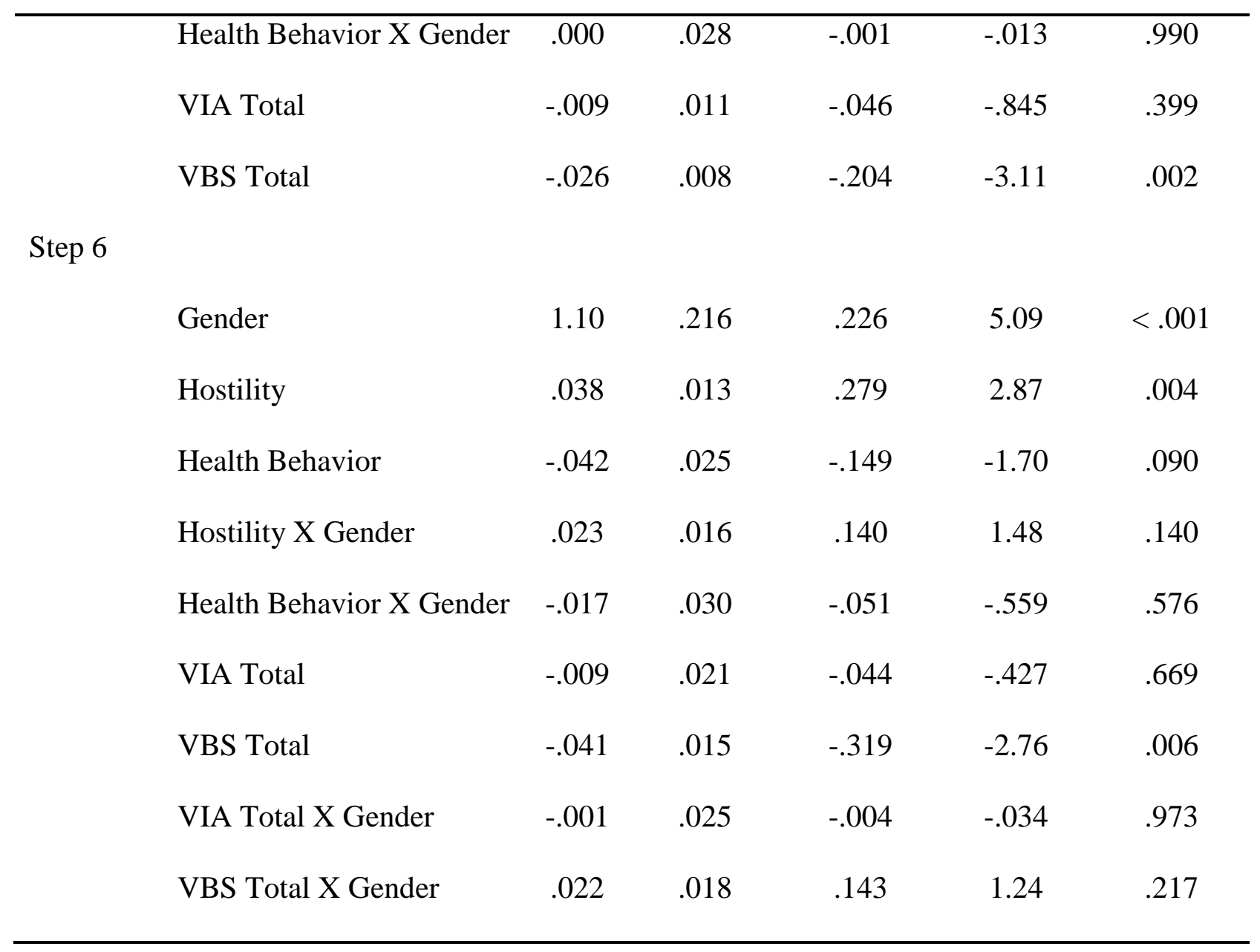


Appendix J: Table 10

Hierarchical Regression Predicting Physical Health, Excluding the VIA.

\begin{tabular}{|c|c|c|c|c|c|}
\hline Variable & $B$ & $S E B$ & $B$ & $t$ & $p$ \\
\hline \multicolumn{6}{|l|}{ Step 1} \\
\hline Gender & .034 & .009 & .152 & 3.96 & $<.001$ \\
\hline \multicolumn{6}{|l|}{ Step 2} \\
\hline Gender & .051 & .008 & .226 & 6.20 & $<.001$ \\
\hline Hostility & .002 & .000 & .365 & 10.00 & $<.001$ \\
\hline \multicolumn{6}{|l|}{ Step 3} \\
\hline Gender & .052 & .008 & .230 & 6.42 & $<.001$ \\
\hline Hostility & .002 & .000 & .326 & 8.88 & $<.001$ \\
\hline Health Behavior & -.002 & .000 & -.178 & -4.94 & $<.001$ \\
\hline \multicolumn{6}{|l|}{ Step 4} \\
\hline Gender & .052 & .008 & .232 & 6.35 & $<.001$ \\
\hline Hostility & .002 & .000 & .321 & 4.70 & $<.001$ \\
\hline Health Behavior & -.003 & .001 & -.234 & -3.73 & $<.001$ \\
\hline Hostility X Gender & $<.001$ & .001 & .007 & .103 & .918 \\
\hline Health Behavior X Gender & .001 & .001 & .069 & 1.09 & .274 \\
\hline \multicolumn{6}{|l|}{ Step 5} \\
\hline Gender & .053 & .008 & .236 & 6.41 & $<.001$ \\
\hline Hostility & .002 & .000 & .305 & 4.32 & $<.001$ \\
\hline Health Behavior & -.003 & .001 & -.223 & -3.47 & .001 \\
\hline Hostility X Gender & $<.001$ & .001 & .008 & .125 & .901 \\
\hline
\end{tabular}


Mediating the Hostility-Health Link 64

\begin{tabular}{|c|c|c|c|c|c|c|}
\hline & Health Behavior X Gender & .001 & .001 & .073 & 1.16 & 247 \\
\hline & VBS Total & .000 & .000 & -.039 & -.868 & .386 \\
\hline \multicolumn{7}{|l|}{ Step 6} \\
\hline & Gender & .054 & .008 & .238 & 6.39 & $<.001$ \\
\hline & Hostility & .002 & .000 & .297 & 3.92 & $<.001$ \\
\hline & Health Behavior & -.003 & .001 & -.216 & -3.22 & .001 \\
\hline & Hostility X Gender & .000 & .001 & .018 & .244 & .808 \\
\hline & Health Behavior X Gender & .001 & .001 & .065 & .944 & .345 \\
\hline & VBS Total & .000 & .000 & -.060 & -.736 & .462 \\
\hline & VBS Total X Gender & .000 & .001 & .025 & .311 & .756 \\
\hline
\end{tabular}


Appendix K: Table 11

Hierarchical Regression Predicting Psychological Health, Excluding the VIA.

\begin{tabular}{|c|c|c|c|c|c|}
\hline Variable & $B$ & $S E B$ & $B$ & $t$ & $p$ \\
\hline \multicolumn{6}{|l|}{ Step 1} \\
\hline Gender & .221 & .190 & .045 & 1.16 & .246 \\
\hline \multicolumn{6}{|l|}{ Step 2} \\
\hline Gender & .767 & .165 & .156 & 4.66 & $<.001$ \\
\hline Hostility & .076 & .005 & .543 & 16.23 & $<.001$ \\
\hline \multicolumn{6}{|l|}{ Step 3} \\
\hline Gender & .798 & .157 & .162 & 5.08 & $<.001$ \\
\hline Hostility & .068 & .005 & .485 & 14.86 & $<.001$ \\
\hline Health Behavior & -.074 & .009 & -.265 & -8.27 & $<.001$ \\
\hline \multicolumn{6}{|l|}{ Step 4} \\
\hline Gender & .766 & .160 & .156 & 4.79 & $<.001$ \\
\hline Hostility & .064 & .009 & .454 & 7.48 & $<.001$ \\
\hline Health Behavior & -.056 & .016 & -.199 & -3.57 & $<.001$ \\
\hline Hostility X Gender & .006 & .010 & .035 & .585 & .558 \\
\hline Health Behavior X Gender & -.027 & .019 & -.080 & -1.44 & .152 \\
\hline \multicolumn{6}{|l|}{ Step 5} \\
\hline Gender & .828 & .160 & .168 & 5.16 & $<.001$ \\
\hline Hostility & .057 & .009 & .409 & 6.55 & $<.001$ \\
\hline Health Behavior & -.046 & .016 & -.166 & -2.92 & .004 \\
\hline Hostility X Gender & .007 & .010 & .039 & .660 & .510 \\
\hline
\end{tabular}


Mediating the Hostility-Health Link 66

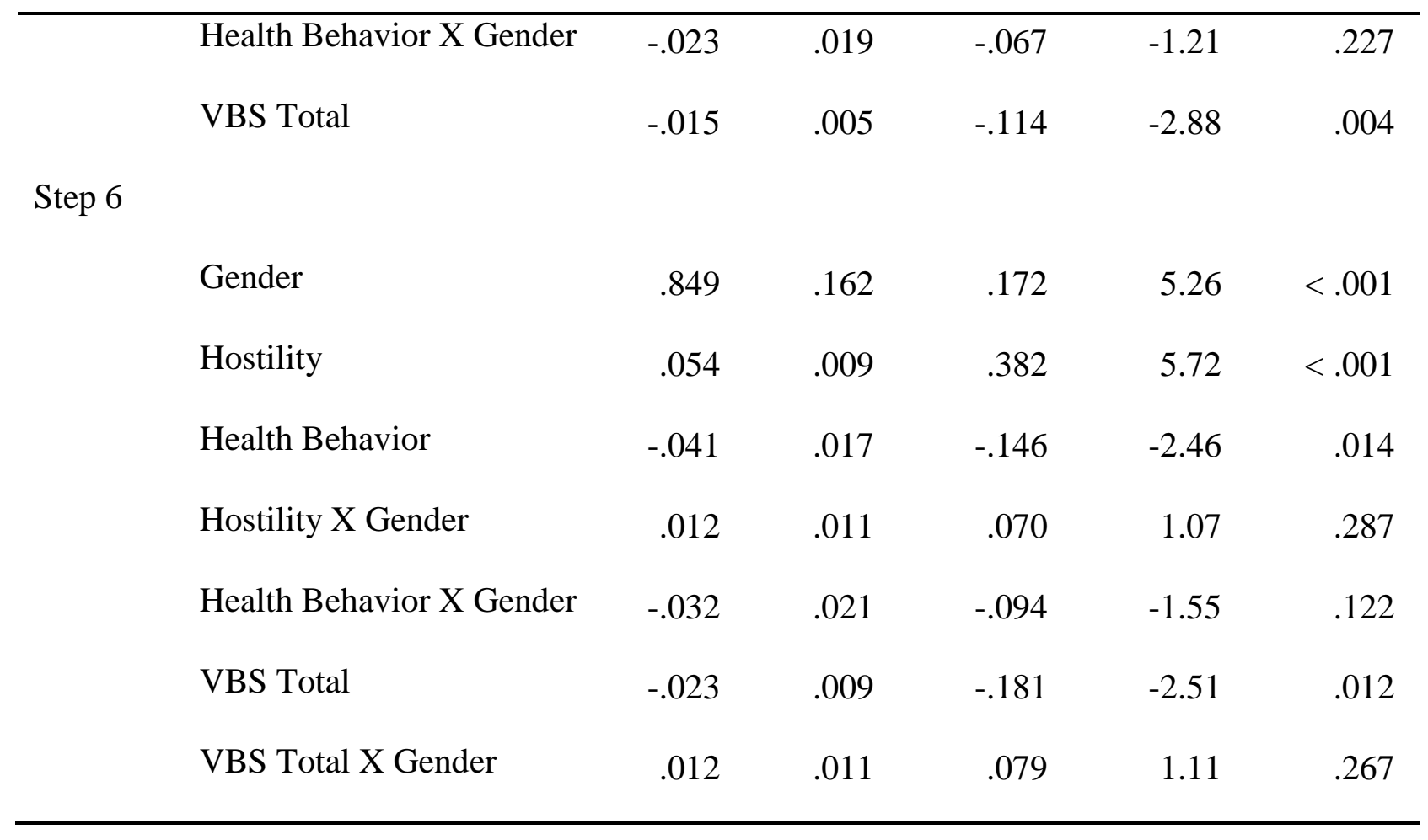


Appendix L: Figure 1. Participant Exclusion Flowchart.

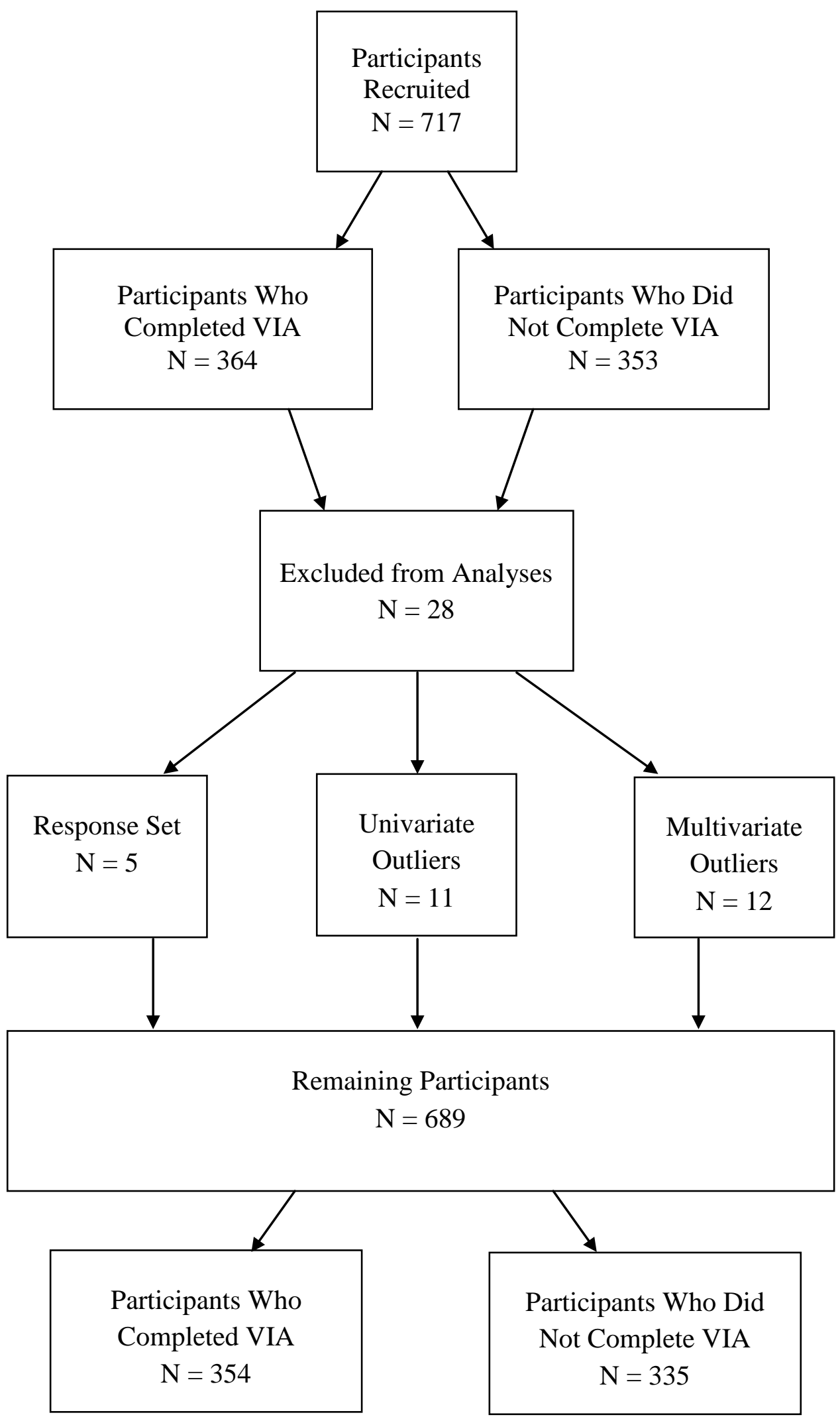


Appendix M: Factor Analyses of the VIA Scale

Peterson and Seligman's 24 character strengths were assessed for issues of multicollinearity. Only 2 of the 24 strengths did not violate multicollinearity, suggesting that the scores from individual character strengths cannot be included in the same analyses. As a result, the factor structure of the VIA subscales was explored further to determine whether factor scores might be used instead of individual scale scores.

Seven confirmatory factor analyses (CFA) were conducted to identify the factor structure most appropriate for the subscales of the VIA. The first structure examined was based on the original structure proposed by Peterson and Seligman (2004; see Table 12 and Figure 2).

The next three models that were tested were derived from exploratory factor analyses (EFA) followed by CFAs using data from the present study. Table 13 depicts the factor structure derived from the EFA of participants who had even-numbered IDs, and Figure 3 represents the associated CFA on data from the participants with even-numbered IDs. Table 14 displays the factor structure derived from the EFA of participants who had odd-numbered IDs, Figure 4 shows the CFA findings based on data from participants with odd-numbered IDs. Table 15 depicts the VIA factor structure derived from an EFA of all participants in the study, and Figure 5 represents the corresponding CFA results.

The last three models examined VIA factor structures proposed by other researchers. Table 16 displays the factor structure proposed by MacDonald, Bore, and Munro (2008) and Figure 6 represents the CFA results. Table 17 shows the VIA factor structure proposed by Ruch et al. (2010) and Figure 7 represents the CFA findings. Lastly, Table 18 depicts the factor structure proposed by Singh and Choubisa (2010), and Figure 8 represents the CFA results. 
As seen in Table 19, the model fit of all seven CFAs was poor. As a result, none of these factor structures were used in the study analyses. A forced one-factor structure (see Table 20) resulted in good fit for all 24 variables; therefore, a composite value of the VIA was used in the study analyses. 
Appendix N: Table 12

Factor Structure of the VIA Proposed by Peterson and Seligman (2004).

\begin{tabular}{|c|c|c|c|c|c|c|}
\hline Variable & Wisdom & Courage & Humanity & Justice & Temperance & Transcendence \\
\hline Appreciation & & & & & & $\mathrm{X}$ \\
\hline Bravery & & $X$ & & & & \\
\hline Citizenship & & & & $\mathrm{X}$ & & \\
\hline Creativity & X & & & & & \\
\hline Curiosity & $\mathrm{X}$ & & & & & \\
\hline Fairness & & & & $\mathrm{X}$ & & \\
\hline Forgiveness & & & & & $X$ & \\
\hline Gratitude & & & & & & $\mathrm{X}$ \\
\hline Honesty & & $X$ & & & & \\
\hline Hope & & & & & & $\mathrm{X}$ \\
\hline Humility & & & & & $\mathrm{X}$ & \\
\hline Humor & & & & & & $\mathrm{X}$ \\
\hline Judgment & $\mathrm{X}$ & & & & & \\
\hline Kindness & & & $\mathrm{X}$ & & & \\
\hline Leadership & & & & $\mathrm{X}$ & & \\
\hline Love & & & $\mathrm{X}$ & & & \\
\hline Love of learning & $\mathrm{X}$ & & & & & \\
\hline Perseverance & & $\mathrm{X}$ & & & & \\
\hline Perspective & $\mathrm{X}$ & & & & & \\
\hline
\end{tabular}


Mediating the Hostility-Health Link 71

\begin{tabular}{|c|c|c|c|c|c|c|}
\hline Variable & Wisdom & Courage & Humanity & Justice & Temperance & Transcendence \\
\hline Prudence & & & & & $\mathrm{X}$ & \\
\hline Religiousness & & & & & & $\mathrm{X}$ \\
\hline Self-regulation & & & & & $\mathrm{X}$ & \\
\hline Social IQ & & & $\mathrm{X}$ & & & \\
\hline Vitality & & $\mathrm{X}$ & & & & \\
\hline
\end{tabular}


Appendix O: Figure 2. Confirmatory Factor Analysis of VIA Factor Structure Proposed by Peterson and Seligman (2004).

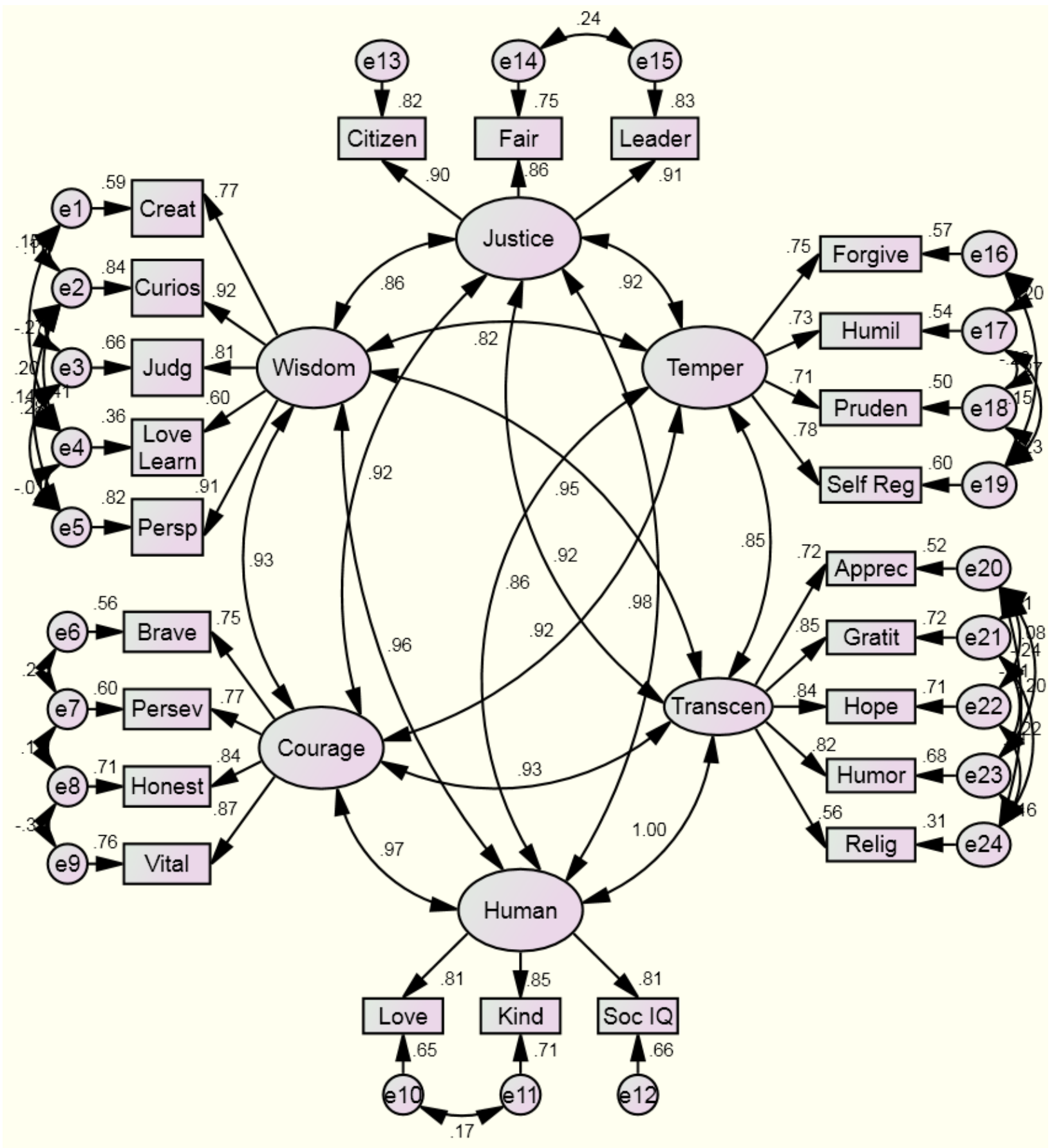


Appendix P: Table 13

Factor Structure of VIA Derived from EFA of Participants with Even-numbered IDs $(n=181)$.

\begin{tabular}{|c|c|c|c|}
\hline Variable & Factor 1 & Factor 2 & Factor 3 \\
\hline Appreciation & .452 & .412 & .482 \\
\hline Bravery & & .725 & .452 \\
\hline Citizenship & .713 & .495 & \\
\hline Creativity & & .808 & \\
\hline Curiosity & .404 & .773 & \\
\hline Fairness & .811 & & \\
\hline Forgiveness & .726 & & \\
\hline Gratitude & 640 & .438 & .424 \\
\hline Honesty & .686 & .400 & \\
\hline Hope & & .589 & .489 \\
\hline Humility & .762 & & .420 \\
\hline Humor & .576 & .718 & \\
\hline Judgment & .535 & & .551 \\
\hline Kindness & .761 & .442 & \\
\hline Leadership & .653 & .510 & .415 \\
\hline Love & .603 & .483 & \\
\hline Love of learning & & .490 & .498 \\
\hline Perseverance & & .433 & .697 \\
\hline Perspective & .504 & .540 & .496 \\
\hline Prudence & .479 & & .783 \\
\hline
\end{tabular}


Mediating the Hostility-Health Link 74

\begin{tabular}{llll}
\hline \multicolumn{1}{c}{ Variable } & Factor 1 & Factor 2 & Factor 3 \\
\hline Religiousness & & & .576 \\
Self-regulation & & & .731 \\
Social IQ & .455 & .666 & \\
Vitality & & .678 & .434 \\
\hline
\end{tabular}


Appendix Q: Figure 3. CFA on Data from Even-numbered Participants Derived from EFA of Participants with Even-numbered IDs.

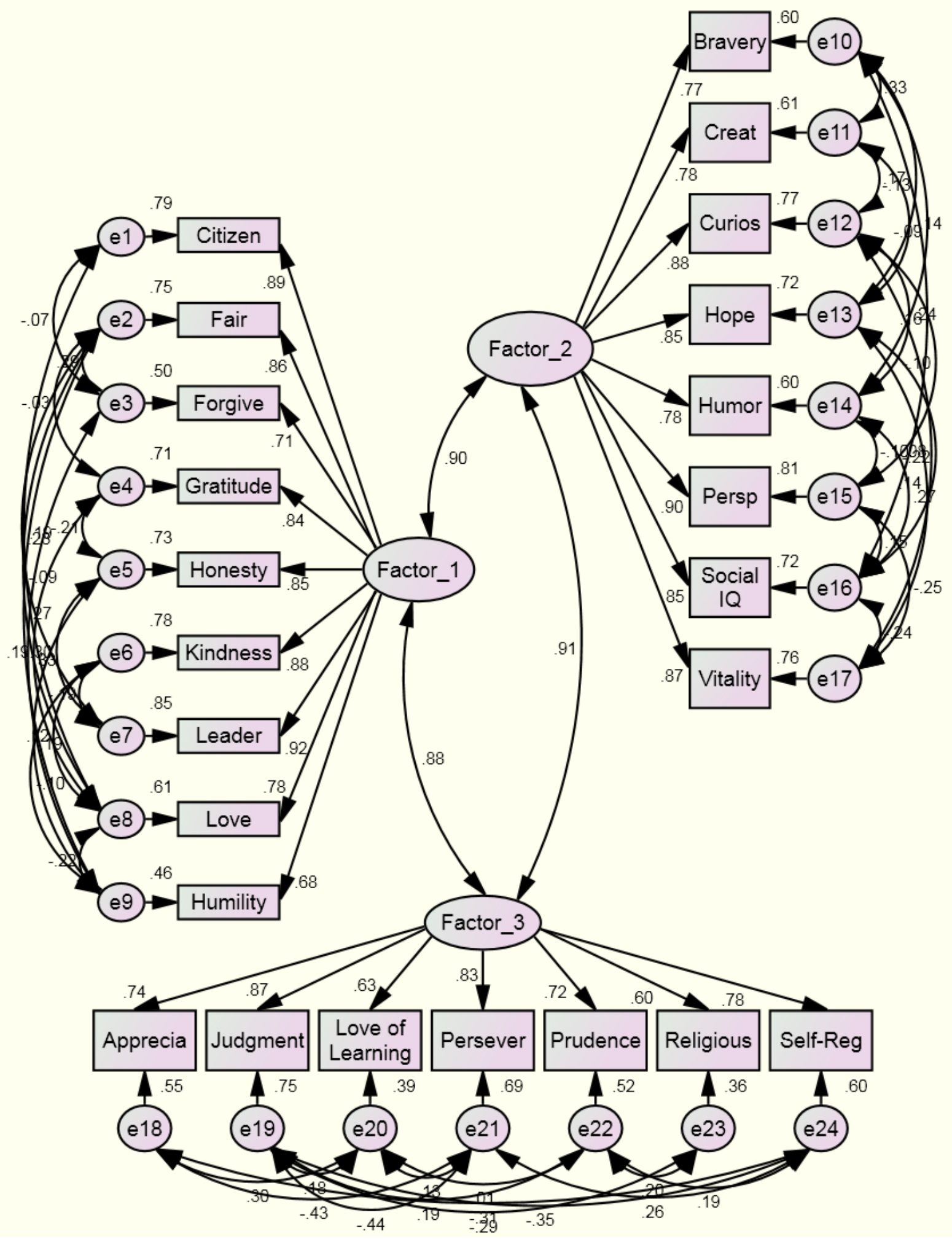


Appendix R: Table 14

Factor Structure of VIA Derived from EFA of Participants of Odd-numbered IDs $(n=180)$.

\begin{tabular}{|c|c|c|c|c|}
\hline Variable & Factor 1 & Factor 2 & Factor 3 & Factor 4 \\
\hline Appreciation & & & .755 & \\
\hline Bravery & .523 & & & .613 \\
\hline Citizenship & .614 & .544 & & \\
\hline Creativity & .440 & & .574 & .532 \\
\hline Curiosity & .671 & & .490 & \\
\hline Fairness & .588 & .573 & & \\
\hline Forgiveness & .505 & .633 & & \\
\hline Gratitude & .548 & .529 & & \\
\hline Honesty & .570 & .463 & & .450 \\
\hline Hope & .564 & .444 & & .403 \\
\hline Humility & & .743 & & \\
\hline Humor & .826 & & & \\
\hline Judgment & .438 & & .603 & \\
\hline Kindness & .752 & & & \\
\hline Leadership & .649 & .489 & & \\
\hline Love & .753 & & & \\
\hline Love of learning & & & .831 & \\
\hline Perseverance & & & & .726 \\
\hline Perspective & .606 & & .461 & \\
\hline Prudence & & .770 & & \\
\hline
\end{tabular}


Mediating the Hostility-Health Link 77

\begin{tabular}{|c|c|c|c|c|}
\hline Variable & Factor 1 & Factor 2 & Factor 3 & Factor 4 \\
\hline Religiousness & & .701 & & \\
\hline Self-regulation & & .470 & & .709 \\
\hline Social IQ & .745 & & & \\
\hline Vitality & .581 & & & .504 \\
\hline
\end{tabular}


Appendix S: Figure 4. CFA on Data from Odd-numbered Participants Derived from EFA of Participants with Odd-numbered IDs.
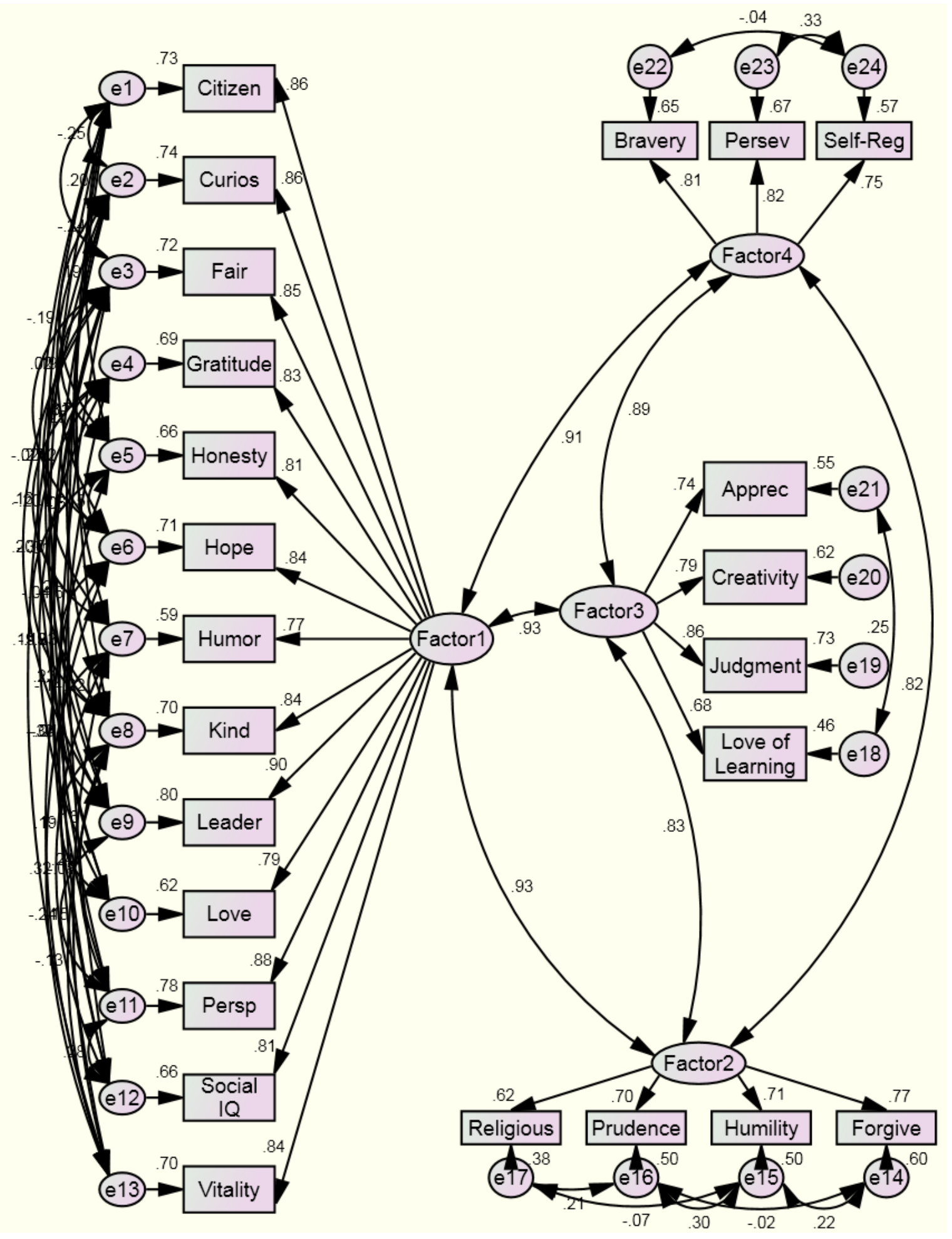
Appendix T: Table 15

Factor Structure of VIA Derived from EFA of All Participants $(n=361)$.

\begin{tabular}{|c|c|c|c|}
\hline Variable & Factor 1 & Factor 2 & Factor 3 \\
\hline Appreciation & & .553 & .421 \\
\hline Bravery & & .773 & \\
\hline Citizenship & .749 & & \\
\hline Creativity & & .838 & \\
\hline Curiosity & .515 & .721 & \\
\hline Fairness & .740 & & .425 \\
\hline Forgiveness & .657 & & .420 \\
\hline Gratitude & .595 & & .472 \\
\hline Honesty & .677 & & \\
\hline Hope & .494 & .536 & .423 \\
\hline Humility & .589 & & .608 \\
\hline Humor & .746 & .503 & \\
\hline Judgment & .424 & .531 & .482 \\
\hline Kindness & .762 & & \\
\hline Leadership & .675 & .437 & .416 \\
\hline Love & .651 & .465 & \\
\hline Love of learning & & .622 & .436 \\
\hline Perseverance & & .516 & .563 \\
\hline Perspective & .506 & .623 & \\
\hline Prudence & & & .840 \\
\hline
\end{tabular}


Mediating the Hostility-Health Link 80

\begin{tabular}{lccc}
\hline Variable & Factor 1 & Factor 2 & Factor 3 \\
\hline Religiousness & & & .608 \\
Self-regulation & & .461 & .639 \\
Social intelligence & .569 & .640 & \\
Vitality & .467 & .654 & \\
\hline
\end{tabular}


Appendix U: Figure 5. CFA Derived from EFA of All Participants.

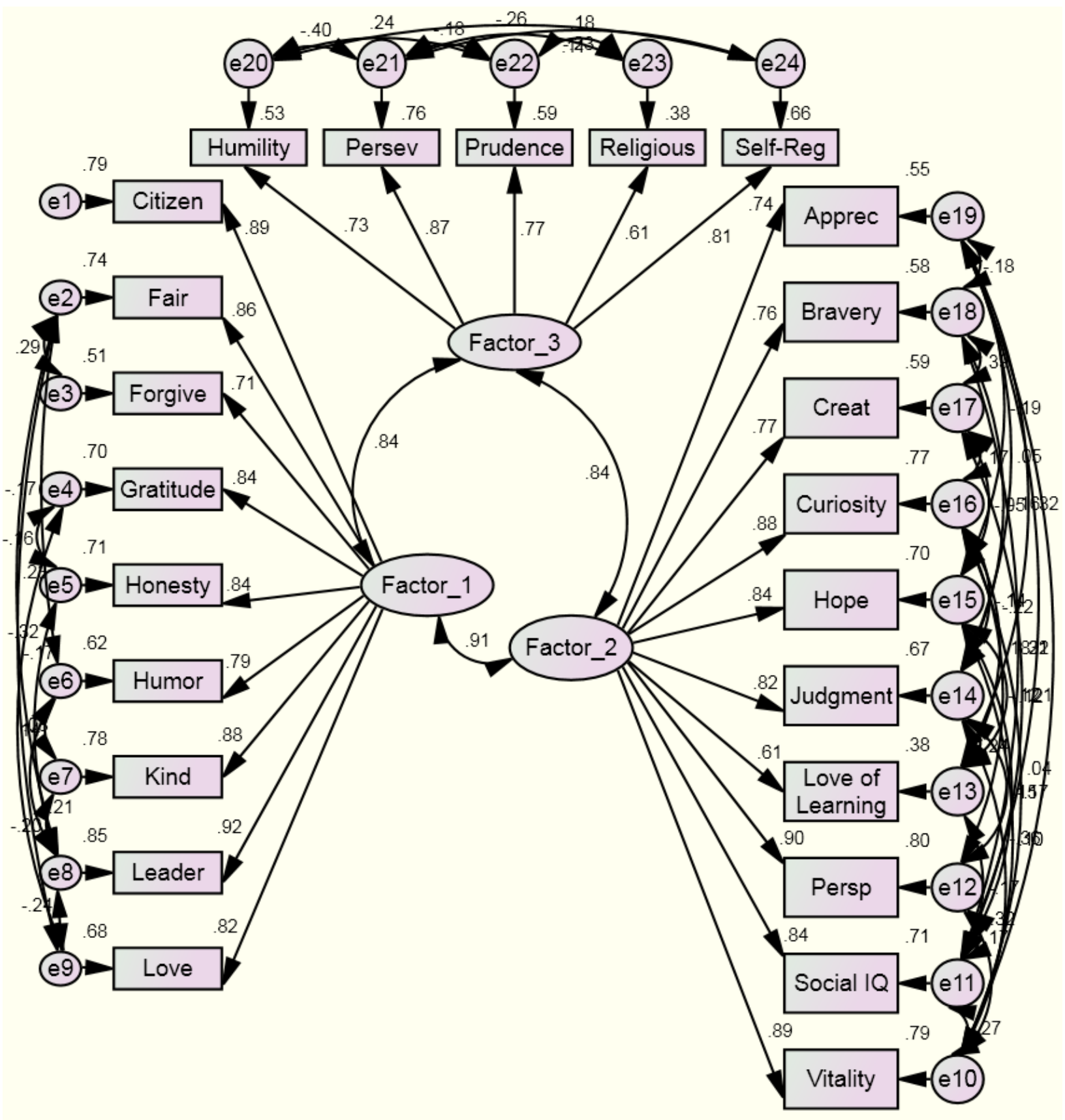


Appendix V: Table 16

Factor Structure of VIA Proposed by MacDonald, Bore, and Munro (2008).

\begin{tabular}{|c|c|c|c|c|}
\hline Variable & Positivity & Intellect & Conscientious & Niceness \\
\hline Appreciation & & $\mathrm{X}$ & & \\
\hline Bravery & & $\mathrm{X}$ & & \\
\hline Citizenship & $\mathrm{X}$ & & & \\
\hline Creativity & & $\mathrm{X}$ & & \\
\hline Curiosity & & $\mathrm{X}$ & & \\
\hline Fairness & & & & $\mathrm{X}$ \\
\hline Forgiveness & & & & $\mathrm{X}$ \\
\hline Gratitude & & & & $\mathrm{X}$ \\
\hline Honesty & & & $\mathrm{X}$ & \\
\hline Hope & $\mathrm{X}$ & & & \\
\hline Humility & & & & $\mathrm{X}$ \\
\hline Humor & $\mathrm{X}$ & & & \\
\hline Judgment & & & $\mathrm{X}$ & \\
\hline Kindness & & & & $\mathrm{X}$ \\
\hline Leadership & $\mathrm{X}$ & & & \\
\hline Love & $\mathrm{X}$ & & & \\
\hline Love of learning & & $\mathrm{X}$ & & \\
\hline Perseverance & & & $\mathrm{X}$ & \\
\hline Perspective & & $\mathrm{X}$ & & \\
\hline
\end{tabular}


Mediating the Hostility-Health Link 83

\begin{tabular}{|c|c|c|c|c|}
\hline Variable & Positivity & Intellect & Conscientious & Niceness \\
\hline Prudence & & & $\mathrm{X}$ & \\
\hline Religiousness & & & & $\mathrm{X}$ \\
\hline Self-regulation & & & $\mathrm{X}$ & \\
\hline Social IQ & & $\mathrm{X}$ & & \\
\hline Vitality & $\mathrm{X}$ & & & \\
\hline
\end{tabular}


Appendix W: Figure 6. CFA of VIA Factor Structure Proposed by MacDonald, Bore, and Munro (2008).

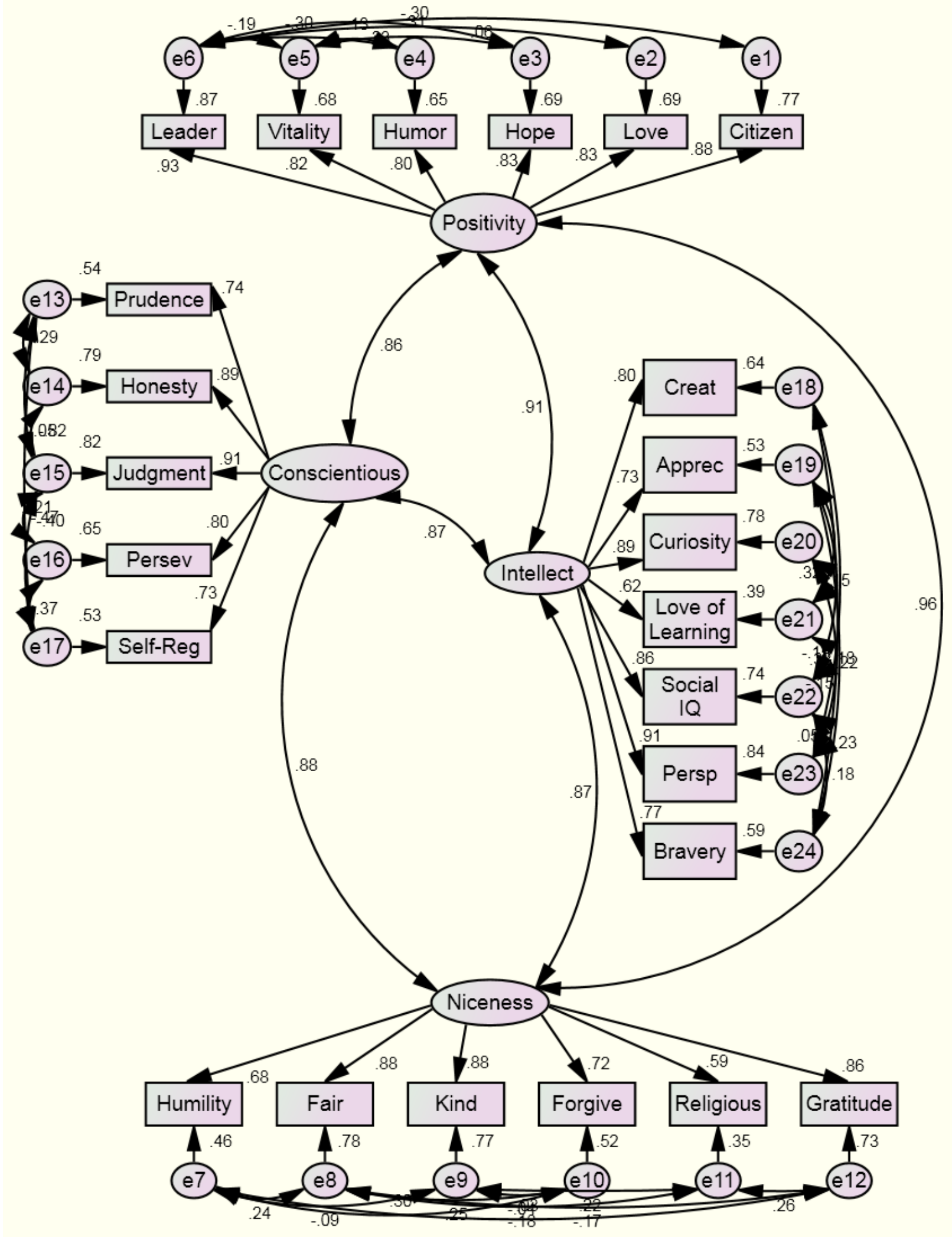


Appendix X: Table 17

Factor Structure of VIA Proposed by Ruch et al. (2010).

\begin{tabular}{|c|c|c|c|c|c|}
\hline Variable & $\begin{array}{l}\text { Emotional } \\
\text { Strengths }\end{array}$ & $\begin{array}{c}\text { Interpersonal } \\
\text { Strengths }\end{array}$ & $\begin{array}{c}\text { Strengths of } \\
\text { Restraint }\end{array}$ & $\begin{array}{l}\text { Intellectual } \\
\text { Strengths }\end{array}$ & $\begin{array}{l}\text { Theological } \\
\text { Strengths }\end{array}$ \\
\hline Appreciation & & & & & $\mathrm{X}$ \\
\hline Bravery & $\mathrm{X}$ & & & & \\
\hline Citizenship & & $\mathrm{X}$ & & & \\
\hline Creativity & & & & $\mathrm{X}$ & \\
\hline Curiosity & & & & $\mathrm{X}$ & \\
\hline Fairness & & $\mathrm{X}$ & & & \\
\hline Forgiveness & & $\mathrm{X}$ & & & \\
\hline Gratitude & & & & & $\mathrm{X}$ \\
\hline Honesty & & & $\mathrm{X}$ & & \\
\hline Hope & $\mathrm{X}$ & & & & \\
\hline Humility & & $X$ & & & \\
\hline Humor & $\mathrm{X}$ & & & & \\
\hline Judgment & & & & $\mathrm{X}$ & \\
\hline Kindness & & $\mathrm{X}$ & & & \\
\hline Leadership & & $\mathrm{X}$ & & & \\
\hline Love & $X$ & & & & \\
\hline Love of & & & & $\mathrm{X}$ & \\
\hline learning & & & & & \\
\hline
\end{tabular}


Mediating the Hostility-Health Link 86

\begin{tabular}{|c|c|c|c|c|c|}
\hline Variable & $\begin{array}{l}\text { Emotional } \\
\text { Strengths }\end{array}$ & $\begin{array}{c}\text { Interpersonal } \\
\text { Strengths }\end{array}$ & $\begin{array}{c}\text { Strengths of } \\
\text { Restraint }\end{array}$ & $\begin{array}{l}\text { Intellectual } \\
\text { Strengths }\end{array}$ & $\begin{array}{c}\text { Theological } \\
\text { Strengths }\end{array}$ \\
\hline Perseverance & & & $\mathrm{X}$ & & \\
\hline Perspective & & & $\mathrm{X}$ & & \\
\hline Prudence & & & $\mathrm{X}$ & & \\
\hline Religiousness & & & & & $\mathrm{X}$ \\
\hline Self-regulation & & & $\mathrm{X}$ & & \\
\hline Social IQ & $\mathrm{X}$ & & & & \\
\hline Vitality & $\mathrm{X}$ & & & & \\
\hline
\end{tabular}


Appendix Y: Figure 7. CFA of VIA Factor Structure Proposed by Ruch et al. (2010).

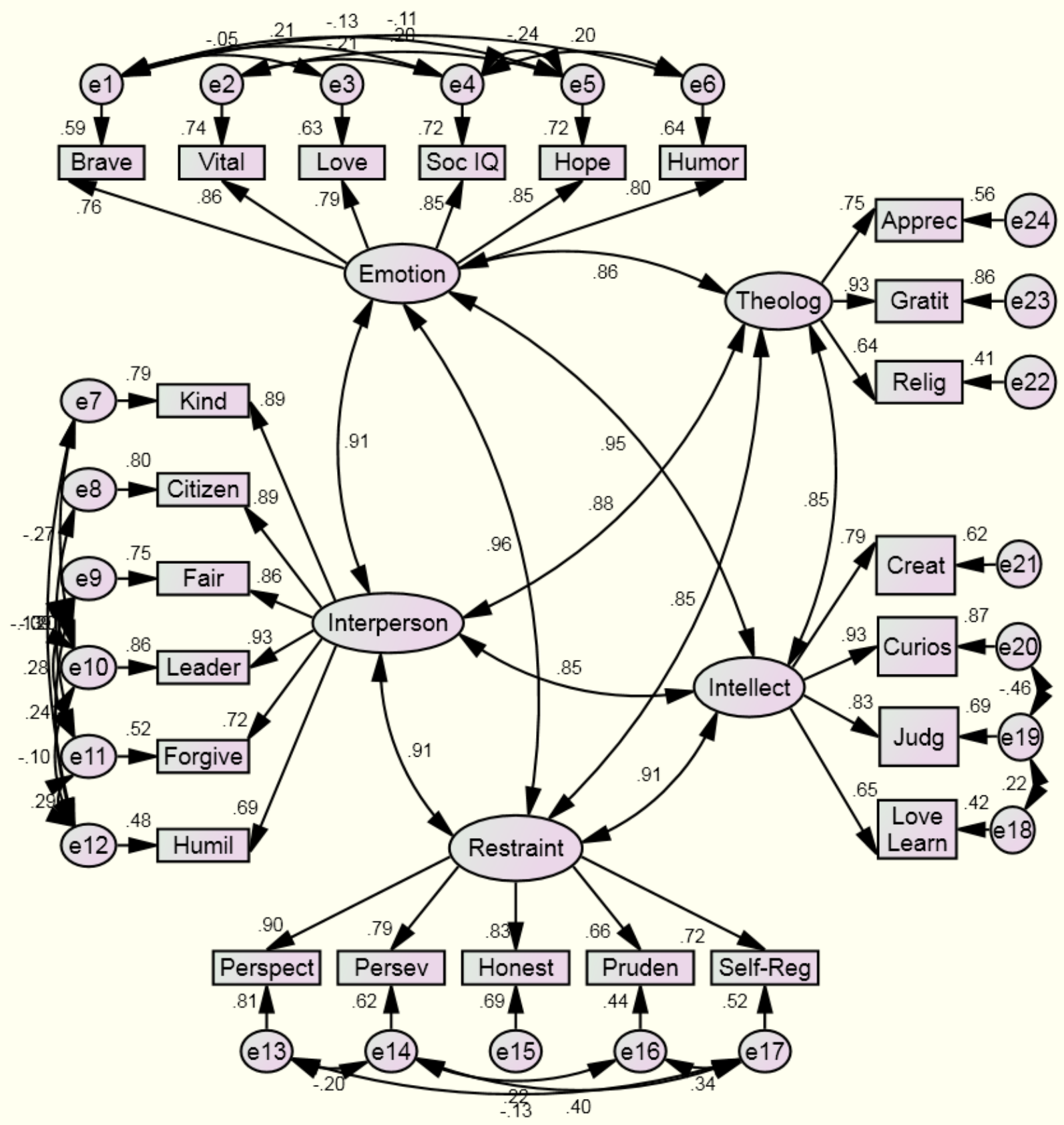


Appendix Z: Table 18

Factor Structure of VIA Proposed by Singh and Choubisa (2010).

\begin{tabular}{|c|c|c|c|c|c|}
\hline \multirow[t]{2}{*}{ Variable } & Civic & Self-assurance & Interpersonal & Intellectual & Theological \\
\hline & Strengths & Strengths & Strengths & Strengths & Strengths \\
\hline Appreciation & & & & & $\bar{X}$ \\
\hline Bravery & & & $X$ & & \\
\hline Citizenship & $\mathrm{X}$ & & & & \\
\hline Creativity & & & & $\mathrm{X}$ & \\
\hline Curiosity & & & & $\mathrm{X}$ & \\
\hline Fairness & $\mathrm{X}$ & & & & \\
\hline Forgiveness & & & & & $\mathrm{X}$ \\
\hline Gratitude & & & & & $\mathrm{X}$ \\
\hline Honesty & $\mathrm{X}$ & & & & \\
\hline Hope & & $\mathrm{X}$ & & & \\
\hline Humility & $\mathrm{X}$ & & & & \\
\hline Humor & & & $\mathrm{X}$ & & \\
\hline Judgment & & & & $\mathrm{X}$ & \\
\hline Kindness & & & $\mathrm{X}$ & & \\
\hline Leadership & $\mathrm{X}$ & & & & \\
\hline Love & & & & & $\mathrm{X}$ \\
\hline Love of & & & & $X$ & \\
\hline learning & & & & & \\
\hline
\end{tabular}


Mediating the Hostility-Health Link 89

\begin{tabular}{|c|c|c|c|c|c|}
\hline Variable & $\begin{array}{c}\text { Civic } \\
\text { Strengths }\end{array}$ & $\begin{array}{c}\text { Self-assurance } \\
\text { Strengths }\end{array}$ & $\begin{array}{c}\text { Interpersonal } \\
\text { Strengths }\end{array}$ & $\begin{array}{l}\text { Intellectual } \\
\text { Strengths }\end{array}$ & $\begin{array}{l}\text { Theological } \\
\text { Strengths }\end{array}$ \\
\hline Perseverance & & $\mathrm{X}$ & & & \\
\hline Perspective & & & & $\mathrm{X}$ & \\
\hline Prudence & $\mathrm{X}$ & & & & \\
\hline Religiousness & & $\mathrm{X}$ & & & \\
\hline Self- & & $\mathrm{X}$ & & & \\
\hline regulation & & & & & \\
\hline Social IQ & & & $\mathrm{X}$ & & \\
\hline Vitality & & $X$ & & & \\
\hline
\end{tabular}


Appendix AA: Figure 8. CFA of VIA Factor Structure Proposed by Singh and Choubisa (2010).

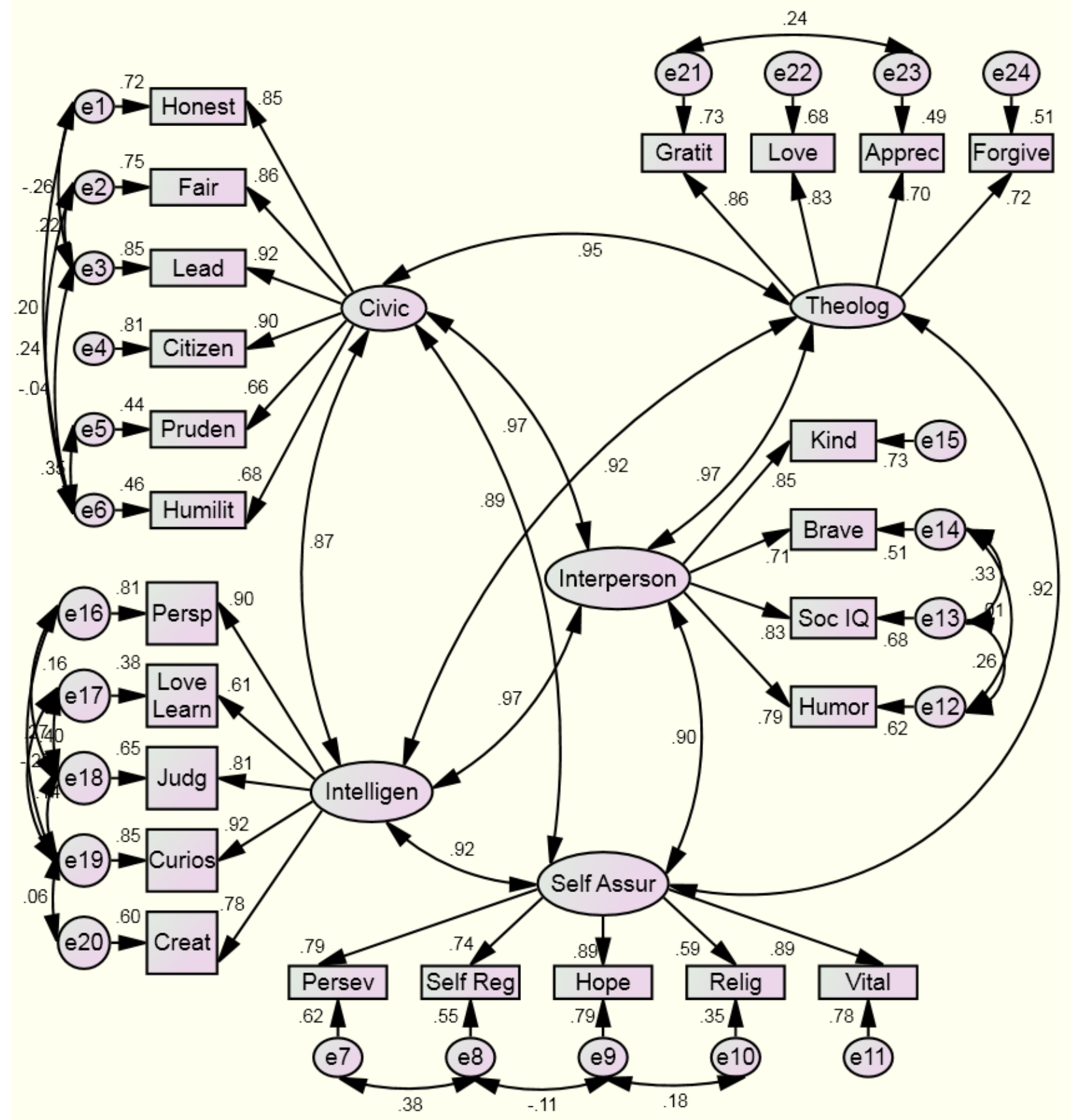


Appendix AB: Table 19

Model Fit of CFAs for Proposed VIA Factor Structure.

\begin{tabular}{lccc}
\hline Source of Factor Structure & CMIN/DF & CFI & RMSEA \\
\hline Peterson and Seligman (2004) & 6.574 & .867 & .124 \\
MacDonald, Bore, and Munro (2008) & 5.855 & .884 & .116 \\
Ruch et al. (2010) & 6.176 & .872 & .120 \\
Singh and Choubisa (2010) & 6.158 & .870 & .120 \\
EFA of Even-Numbered Participants & 5.038 & .907 & .106 \\
EFA of Odd-Numbered Participants & 6.025 & .890 & .118 \\
EFA of All Participants & 5.475 & .897 & .111 \\
\hline
\end{tabular}


Appendix AC: Table 20

Forced One-factor Factor Structure of VIA Derived from EFA of All Participants $(n=361)$.

\begin{tabular}{lc}
\hline Variable & Factor 1 \\
\hline Appreciation & .724 \\
Bravery & .742 \\
Citizenship & .858 \\
Creativity & .740 \\
Curiosity & .858 \\
Fairness & .839 \\
Forgiveness & .725 \\
Gratitude & .843 \\
Honesty & .822 \\
Hope & .841 \\
Humility & .675 \\
Humor & .774 \\
Judgment & .822 \\
Kindness & .844 \\
Leadership & .894 \\
Love & .801 \\
Love of learning & .631 \\
Perseverance & .700 \\
Perspective & \\
\hline
\end{tabular}


Mediating the Hostility-Health Link 93

\begin{tabular}{lc}
\hline Variable & Factor 1 \\
\hline Religiousness & .603 \\
Self-regulation & .732 \\
Social intelligence & .823 \\
Vitality & .846 \\
\hline
\end{tabular}

